\title{
Quantifying aerosol mixing state with entropy and diversity measures
}

\author{
N. Riemer ${ }^{1}$ and M. West ${ }^{2}$ \\ ${ }^{1}$ Department of Atmospheric Sciences, University of Illinois at Urbana-Champaign, IL, USA \\ ${ }^{2}$ Department of Mechanical Science and Engineering, University of Illinois at Urbana-Champaign, IL, USA
}

Correspondence to: N. Riemer (nriemer@illinois.edu)

Received: 12 May 2013 - Published in Atmos. Chem. Phys. Discuss.: 12 June 2013

Revised: 14 September 2013 - Accepted: 30 September 2013 - Published: 25 November 2013

\begin{abstract}
This paper presents the first quantitative metric for aerosol population mixing state, defined as the distribution of per-particle chemical species composition. This new metric, the mixing state index $\chi$, is an affine ratio of the average per-particle species diversity $D_{\alpha}$ and the bulk population species diversity $D_{\gamma}$, both of which are based on information-theoretic entropy measures. The mixing state index $\chi$ enables the first rigorous definition of the spectrum of mixing states from so-called external mixture to internal mixture, which is significant for aerosol climate impacts, including aerosol optical properties and cloud condensation nuclei activity. We illustrate the usefulness of this new mixing state framework with model results from the stochastic particle-resolved model PartMC-MOSAIC. These results demonstrate how the mixing state metrics evolve with time for several archetypal cases, each of which isolates a specific process such as coagulation, emission, or condensation. Further, we present an analysis of the mixing state evolution for a complex urban plume case, for which these processes occur simultaneously. We additionally derive theoretical properties of the mixing state index and present a family of generalized mixing state indexes that vary in the importance assigned to low-mass-fraction species.
\end{abstract}

\section{Introduction}

Our quantitative understanding of the aerosol impact on climate still has large gaps and hence introduces large uncertainties in climate predictions (IPCC, 2007). One of the challenges is the inherently multi-scale nature of the problem: the macro-scale impacts of aerosol particles are governed by processes that occur on the particle-scale, and these microscale processes are difficult to represent in large-scale models (Ghan and Schwartz, 2007).

An important quantity in this context is the so-called mixing state of the aerosol population, which we define as the distribution of the per-particle chemical species compositions. Recent observations made in the laboratory and in the field using single-particle measurement techniques have revealed that the mixing states of ambient aerosol populations are complex. Even freshly emitted particles can have complex compositions by the time they enter the atmosphere. For example, the mixing state of particles originating from vehicle engines depends strongly on fuel type and operating conditions (Toner et al., 2006). The initial particle composition is further modified in the atmosphere as a result of aging processes including coagulation, condensation of secondary aerosol species, and heterogeneous reactions (Weingartner et al., 1997).

While the extent to which mixing state needs to be represented in models is still an open research question, there is evidence that mixing state matters for adequately modeling aerosol properties such as optical properties (Jacobson, 2001; Chung and Seinfeld, 2005; Zaveri et al., 2010), cloud condensation nuclei activity (Zaveri et al., 2010), and wet removal (Koch et al., 2009; Stier et al., 2006; Liu et al., 2012). Therefore, in recent years, efforts have been made to represent mixing state in models to some extent. This is the case for models on the regional scale (Riemer et al., 2003) as well as on the global scale (Jacobson, 2002; Stier et al., 2005; Bauer et al., 2008; Wilson et al., 2001).

In discussions about mixing state, the terms "external mixture" and "internal mixture" are frequently used to describe 
how different chemical species are distributed over the particle population. An external mixture consists of particles that each contain only one pure species (which may be different for different particles), whereas an internal mixture describes a particle population where different species are present within one particle. If all particles consist of the same species mixture and the relative abundances are identical, the term "fully internal mixture" is commonly used.

While these terms may be appropriate for idealized cases, observational evidence shows that ambient aerosol populations rarely fall in these two simple categories. In this paper we present the first quantitative measure of aerosol mixing state, the mixing state index $\chi$, based on diversity measures derived from the information-theoretic entropy of the chemical species distribution among particles.

The measurement of species diversity and distribution using information-theoretic entropy measures has a long history in many scientific fields. In ecology, the study of animal and plant species diversity within an environment dates back to Good (1953) and MacArthur (1955), but rose to prominence with the work of Whittaker $(1960,1965,1972)$. Whittaker proposed measuring species diversity by the species richness (number of species), the Shannon entropy, and the Simpson index, which are now referred to as generalized diversities of order 0,1 , and 2, respectively (see Appendix A for details).

Whittaker also introduced the fundamental concepts of alpha, beta, and gamma diversity, where alpha diversity $D_{\alpha}$ measures the average species diversity within a local area, beta diversity $D_{\beta}$ measures the diversity between local areas, and $D_{\gamma}$ measures the overall species diversity within the environment, given as the product of alpha and beta diversities. In the context of aerosols, we regard alpha diversity as measuring the average species diversity within a single particle, beta diversity as quantifying diversity between particles, and gamma diversity as describing the overall diversity in bulk population (see Section 2 for details). From these measures we construct the mixing state index $\chi$ as an affine ratio of alpha and gamma diversity.

The ecology literature in the 1960s and 1970s contains much work on species diversity and distribution, although there was also significant confusion about the underlying mathematical framework (Hurlbert, 1971; Hill, 1973). Within the last decade, the profusion of diversity measures have been largely categorized (Tuomisto, 2013, 2012, 2010), although disagreement in the literature is still present (Tuomisto, 2011; Gorelick, 2011; Jurasinski and Koch, 2011; Moreno and Rodríguez, 2011). Despite the current controversies, certain principles are now well-established, such as the use of the effective number of species as the fundamentally correct way to measure diversity (Hill, 1973; Jost, 2006; Chao et al., 2008, 2010; Jost et al., 2010).

As well as the basic mathematical framework of measuring diversity, there has also been much effort on understanding its ecological impacts, with a particular interest in the relationship between ecosystem stability and diversity (MacArthur, 1955; Goodman, 1975; McCann, 2000; Ives and Carpenter, 2007). Other important research questions include the sources of diversity (Tsimring et al., 1996; De'ath, 2012), extensions of diversity to include a concept of species distance Chao et al. (2010); Leinster and Cobbold (2012); Feoli (2012); Scheiner (2012), and techniques for measuring diversity (Chao and Shen, 2003; Schmera and Podani, 2013; Gotelli and Chao, 2013), despite the well-known difficulties in estimating entropy in an unbiased fashion (Harris, 1975; Paninski, 2003). Beyond ecology, the study of diversity is also important in economics (Garrison and Paulson, 1973; Hannah and Kay, 1977; Attaran and Zwick, 1989; Malizia and Ke, 1993; Drucker, 2013), immunology (Tsimring et al., 1996), neuroscience (Panzeri and Treves, 1996; Strong et al., 1998), and genetics (Innan et al., 1999; Rosenberg et al., 2002; Falush et al., 2007).

This paper is organized as follows. In Sect. 2 we define the well-established entropy and diversity measures, adapted to the aerosol context, and use these to define our new mixing state index $\chi$. This section also contains examples of diversity and mixing state and a summary of the properties of these measures. Section 3 presents a suite of simulations for archetypal cases using the stochastic particle-resolved model PartMC-MOSAIC (Riemer et al., 2009; Zaveri et al., 2008). These simulations show how the diversity and mixing state measures evolve under common atmospheric processes, including emissions, dilution, coagulation, and gas-to-particle conversion. A more complex urban plume simulation is then considered in Sect. 4, for which the above processes occur simultaneously. Appendix A presents a generalization of the diversity and mixing state measures to ascribe different levels of importance to low-mass-fraction species, while Appendix B contains mathematical proofs for the results summarized in Sect. 2.

\section{Entropy, diversity, and mixing state index}

We consider a population of $N$ aerosol particles, each consisting of some amounts of $A$ distinct aerosol species. The mass of species $a$ in particle $i$ is denoted $\mu_{i}^{a}$, for $i=1, \ldots, N$ and $a=1, \ldots, A$. From this basic description of the aerosol particles we can construct all other masses and mass fractions, as detailed in Table 1. Using the distribution of aerosol species within the aerosol particles and within the population, we can now define mixing entropies, species diversities, and the mixing state index, as shown in Table 2. Note that entropy and diversity are equivalent concepts, and that either could be taken as fundamental. We retain both in this paper to enable connections with the historical and current literature.

The entropy $H_{i}$ or diversity $D_{i}$ of a single particle $i$ measures how uniformly distributed the constituent species are within the particle. This ranges from the minimum value 
Table 1. Aerosol mass and mass fraction definitions and notations. The number of particles in the population is $N$, and the number of species is $A$.

\begin{tabular}{ll}
\hline Quantity & Meaning \\
\hline$\mu_{i}^{a}$ & mass of species $a$ in particle $i$ \\
$\mu_{i}=\sum_{a=1}^{A} \mu_{i}^{a}$ & total mass of particle $i$ \\
$\mu^{a}=\sum_{i=1}^{N} \mu_{i}^{a}$ & total mass of species $a$ in population \\
$\mu=\sum_{i=1}^{N} \mu_{i}$ & total mass of population \\
$p_{i}^{a}=\frac{\mu_{i}^{a}}{\mu_{i}}$ & mass fraction of species $a$ in particle $i$ \\
$p_{i}=\frac{\mu_{i}}{\mu}$ & mass fraction of particle $i$ in population \\
$p^{a}=\frac{\mu^{a}}{\mu}$ & mass fraction of species $a$ in population \\
\hline
\end{tabular}

( $\left.H_{i}=0, D_{i}=1\right)$ when the particle is a single pure species, to the maximum value $\left(H_{i}=\ln A, D_{i}=A\right)$ when the particle is composed of equal amounts of all $A$ species. As shown in Fig. 1, the diversity $D_{i}$ of a particle measures the effective number of equally distributed species in the particle. If the particle is composed of equal amounts of 3 species then the number of effective species is 3 , for example, while 3 species unequally distributed will result in an effective number of species somewhat less than 3 .

Extending the single-particle diversity $D_{i}$ to an entire population of particles gives three different measures of population diversity. Alpha diversity $D_{\alpha}$ measures the average perparticle diversity in the population, beta diversity $D_{\beta}$ measures the inter-particle diversity, and gamma diversity $D_{\gamma}$ measures the bulk population diversity. The bulk population diversity $\left(D_{\gamma}\right)$ is the product of diversity on the per-particle level $\left(D_{\alpha}\right)$ and diversity between the particles $\left(D_{\beta}\right)$, giving

$$
\underbrace{D_{\alpha}}_{\begin{array}{c}
\text { per-particle } \\
\text { diversity }
\end{array}} \times \underbrace{D_{\beta}}_{\begin{array}{c}
\text { inter-particle } \\
\text { diversity }
\end{array}}=\underbrace{D_{\gamma} .}_{\begin{array}{c}
\text { bulk population } \\
\text { diversity }
\end{array}}
$$

Alpha diversity $D_{\alpha}$ measures the average per-particle effective number of species in the population, and ranges from 1 when all particles are pure (each composed of just one species, not necessarily all the same), to a maximum when all particles have identical mass fractions. Gamma diversity $D_{\gamma}$ measures the effective number of species in the bulk population, ranging from 1 if the entire population contains just one species, to a maximum when there are equal bulk mass fractions of all species. Beta diversity $D_{\beta}$ is defined by an affine ratio of gamma to alpha diversity, so it measures interparticle diversity and ranges from 1 when all particles have identical mass fractions, to a maximum when every particle is pure but the bulk mass fractions are all equal. Table 3 sum-

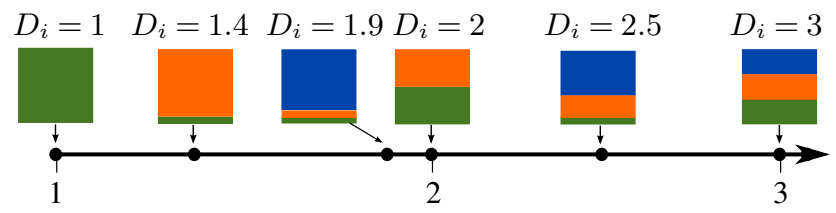

Fig. 1. Particle diversities $D_{i}$ of representative particles. The particle diversity measures the effective number of species within a particle, so a pure single-species particle has $D_{i}=1$ and a particle consisting of 2 or 3 species in even proportion will have $D_{i}=2$ or $D_{i}=3$, respectively. A particle with unequal amounts of 2 species will have an effective number of species somewhat less than 2 , while a particle with unequal amounts of 3 species will have effective species below 3 , and possibly even below 2 if the distribution is very unequal.

marizes the conditions under which the diversity measures attain their maximum and minimum values.

The two population diversities $D_{\alpha}$ (per-particle) and $D_{\gamma}$ (bulk) can be combined to give the single mixing state index $\chi$, which measures the homogeneity or heterogeneity of the population. It ranges from $\chi=0$ when all particles are pure (a fully externally mixed population) to $\chi=1$ when all particles have identical mass fractions (a fully internally mixed population). For example, a population with a mixing state index of $\chi=0.3$ (equivalently, $\chi=30 \%$ ) can be interpreted as being $30 \%$ internally mixed, and thus $70 \%$ externally mixed.

Examples for different population diversities and mixing states are shown graphically in Fig. 2. Because the population diversity $D_{\gamma}$ cannot be less than the per-particle diversity $D_{\alpha}$, only a triangular region is accessible on the mixing state diagram. Representative populations and their diversities are indicated on this diagram, as listed in Table 4.

The diversity measures and mixing state index behave in characteristic ways when the particle population undergoes coagulation or when two particle populations are mixed, as is the case when particles are emitted into a pre-existing population. This is summarized in Table 5. The population mixing results (Table 5 and Theorem 3 ) show that the diversities and entropies are intensive quantities. For example, doubling the size of particle $i$ leaves $H_{i}$ unchanged, and doubling the population leaves $H_{\alpha}$ unchanged. Extensive versions of these quantities can be defined by mass-weighting, so that the total mass-extensive entropy is $H=\sum_{i} \mu_{i} H_{i}$, for example.

\section{Single-process studies}

Having established the key quantities to characterize mixing state, and having explored their properties and their physical interpretation, we illustrate in this section their behavior with a suite of simulation scenarios. The cases presented in this section are "single-process" simulations. They are designed to isolate the impacts of emission, coagulation, and condensation on the aerosol mixing state, and exemplify how each 
Table 2. Definitions of aerosol mixing entropies, particle diversities, and mixing state index. In these definitions we take $0 \ln 0=0$ and $0^{0}=1$.

\begin{tabular}{|c|c|c|c|c|}
\hline Quantity & Name & Units & Range & Meaning \\
\hline$H_{i}=\sum_{a=1}^{A}-p_{i}^{a} \ln p_{i}^{a}$ & $\begin{array}{l}\text { mixing entropy of } \\
\text { particle } i\end{array}$ & - & 0 to $\ln A$ & $\begin{array}{l}\text { Shannon entropy of species dis- } \\
\text { tribution within particle } i\end{array}$ \\
\hline$H_{\alpha}=\sum_{i=1}^{N} p_{i} H_{i}$ & $\begin{array}{l}\text { average particle } \\
\text { mixing entropy }\end{array}$ & - & 0 to $\ln A$ & $\begin{array}{l}\text { average Shannon entropy per } \\
\text { particle }\end{array}$ \\
\hline$H_{\gamma}=\sum_{a=1}^{A}-p^{a} \ln p^{a}$ & $\begin{array}{l}\text { population bulk } \\
\text { mixing entropy }\end{array}$ & - & 0 to $\ln A$ & $\begin{array}{l}\text { Shannon entropy of species dis- } \\
\text { tribution within population }\end{array}$ \\
\hline$D_{i}=e^{H_{i}}=\prod_{a=1}^{A}\left(p_{i}^{a}\right)^{-p_{i}^{a}}$ & $\begin{array}{l}\text { particle diversity } \\
\text { of particle } i\end{array}$ & $\begin{array}{l}\text { effective } \\
\text { species }\end{array}$ & 1 to $A$ & $\begin{array}{l}\text { effective number of species in } \\
\text { particle } i\end{array}$ \\
\hline$D_{\alpha}=e^{H_{\alpha}}=\prod_{i=1}^{N}\left(D_{i}\right)^{p_{i}}$ & $\begin{array}{l}\text { average particle } \\
\text { (alpha) species } \\
\text { diversity }\end{array}$ & $\begin{array}{l}\text { effective } \\
\text { species }\end{array}$ & 1 to $A$ & $\begin{array}{l}\text { average effective number of } \\
\text { species in each particle }\end{array}$ \\
\hline$D_{\gamma}=e^{H_{\gamma}}=\prod_{a=1}^{A}\left(p^{a}\right)^{-p^{a}}$ & $\begin{array}{l}\text { bulk population } \\
\text { (gamma) species } \\
\text { diversity }\end{array}$ & $\begin{array}{l}\text { effective } \\
\text { species }\end{array}$ & 1 to $A$ & $\begin{array}{l}\text { effective number of species in } \\
\text { the population }\end{array}$ \\
\hline$D_{\beta}=\frac{D_{\gamma}}{D_{\alpha}}$ & $\begin{array}{l}\text { inter-particle } \\
\text { (beta) diversity }\end{array}$ & - & 1 to $A$ & $\begin{array}{l}\text { amount of population species di- } \\
\text { versity due to inter-particle di- } \\
\text { versity }\end{array}$ \\
\hline$\chi=\frac{D_{\alpha}-1}{D_{\gamma}-1}$ & mixing state index & - & 0 to $100 \%$ & $\begin{array}{l}\text { degree to which population is } \\
\text { externally mixed }(\chi=0) \text { versus } \\
\text { internally mixed }(\chi=100 \%)\end{array}$ \\
\hline
\end{tabular}

Table 3. Conditions under which the maximum and minimum diversity values are reached. See Fig. 2 for a graphical representation of this information, and see Theorem 1 for precise statements.

\begin{tabular}{|c|c|c|c|c|}
\hline \multirow{2}{*}{$\begin{array}{l}\text { Quantity } \\
D_{i}\end{array}$} & \multicolumn{2}{|c|}{ Minimum value } & \multicolumn{2}{|c|}{ Maximum value } \\
\hline & 1 & when particle $i$ is pure & $A$ & when particle $i$ has all mass fractions equal \\
\hline$D_{\alpha}$ & 1 & when all particles are pure & $D_{\gamma}$ & $\begin{array}{l}\text { when all particles have identical mass frac- } \\
\text { tions }\end{array}$ \\
\hline$D_{\beta}$ & 1 & $\begin{array}{l}\text { when all particles have identical mass frac- } \\
\text { tions }\end{array}$ & $A$ & $\begin{array}{l}\text { when all particles are pure and the bulk } \\
\text { mass fractions are all equal }\end{array}$ \\
\hline$D_{\gamma}$ & $D_{\alpha}$ & $\begin{array}{l}\text { when all particles have identical mass frac- } \\
\text { tions }\end{array}$ & $A$ & when all bulk mass fractions are equal \\
\hline$\chi$ & $0 \%$ & when all particles are pure & $100 \%$ & $\begin{array}{l}\text { when all particles have identical mass frac- } \\
\text { tions }\end{array}$ \\
\hline
\end{tabular}

process impacts the quantities $D_{\alpha}, D_{\gamma}$ and $\chi$. Expanding on this, in Sect. 4 we analyze a more complex urban plume case with emission, dilution, coagulation and condensation occurring simultaneously.

We used the particle-resolved model PartMC-MOSAIC (Particle Monte Carlo Model for Simulating Aerosol Interactions and Chemistry) (Riemer et al., 2009; Zaveri et al., 2008) for this study (PartMC version 2.2.0). This stochastic particle-resolved model explicitly resolves the composition of individual aerosol particles in a population of differ- ent particle types in a Lagrangian air parcel. PartMC simulates particle emissions, dilution with the background, and Brownian coagulation stochastically by generating a realization of a Poisson process. Gas- and aerosol-phase chemistry are treated deterministically by coupling with the MOSAIC chemistry code. The governing model equations and the numerical algorithms are described in detail in Riemer et al. (2009). Since the model tracks the per-particle composition as the population evolves over time, we can calculate the mixing state quantities as detailed in Sect. 2. We excluded 
Table 4. Representative particle populations shown on Fig. 2, with the average per-particle diversity $D_{\alpha}$, the bulk population diversity $D_{\gamma}$, and the mixing state index $\chi$ listed for each population.

\begin{tabular}{|c|c|c|c|c|c|}
\hline & Population & $\begin{array}{l}\text { Per-part. } \\
\text { div. } D_{\alpha}\end{array}$ & $\begin{array}{l}\text { Bulk div. } \\
\qquad D_{\gamma}\end{array}$ & $\begin{array}{l}\text { Mix. state } \\
\text { index } \chi\end{array}$ & Description \\
\hline$\Pi^{1}$ & & 1 & 1 & undefined & all particles identical and just one bulk species \\
\hline$\Pi^{2}$ & & 3 & 3 & $100 \%$ & $\begin{array}{l}\text { all particles identical (fully internally mixed) } \\
\text { with identical bulk fractions }\end{array}$ \\
\hline$\Pi^{3}$ & & 1 & 3 & $0 \%$ & $\begin{array}{l}\text { all particles pure ( } 1 \text { effective species per par- } \\
\text { ticle, fully externally mixed) but identical bulk } \\
\text { fractions ( } 3 \text { effective bulk species) }\end{array}$ \\
\hline$\Pi^{4}$ & & 1 & 1.89 & $0 \%$ & $\begin{array}{l}\text { all particles pure ( } 1 \text { effective species per par- } \\
\text { ticle, fully externally mixed) but less than two } \\
\text { effective bulk species }\end{array}$ \\
\hline$\Pi^{5}$ & & 2.37 & 3 & $68 \%$ & $\begin{array}{l}\text { each particle has less than three effective } \\
\text { species (unequal fractions) but bulk fractions } \\
\text { are identical ( } 3 \text { effective bulk species) }\end{array}$ \\
\hline$\Pi^{6}$ & & 1.89 & 1.89 & $100 \%$ & $\begin{array}{l}\text { all particles are identical (fully internally } \\
\text { mixed) but less than } 2 \text { effective bulk species }\end{array}$ \\
\hline$\Pi^{7}$ & & 1.35 & 2.37 & $26 \%$ & generic state with partial mixing \\
\hline
\end{tabular}

Table 5. Change in population diversities and mixing state index due to change in the particle population. For population combinations the superscript indicates the population for which a quantity is evaluated. For coagulation, $D_{\alpha}, D_{\beta}$, and $\chi$ stay constant when all particles have identical mass fractions. See Theorems 2 and 3 for precise statements.

\begin{tabular}{lll}
\hline Quantity & Change due to coagulation & Combination of populations $\Pi^{X}$ and $\Pi^{Y}$ into $\Pi^{Z}$ \\
\hline$D_{\alpha}$ & increases (or constant) & $\min \left(D_{\alpha}^{X}, D_{\alpha}^{Y}\right) \leq D_{\alpha}^{Z} \leq \max \left(D_{\alpha}^{X}, D_{\alpha}^{Y}\right)$ \\
$D_{\beta}$ & decreases (or constant) & $\min \left(D_{\beta}^{X}, D_{\beta}^{Y}\right) \leq D_{\beta}^{Z}$ \\
$D_{\gamma}$ & constant & $\min \left(D_{\gamma}^{X}, D_{\gamma}^{Y}\right) \leq D_{\gamma}^{Z}$ \\
$\chi$ & increases (or constant) & $\chi^{Z} \leq \max \left(\chi^{X}, \chi^{Y}\right)$ \\
\hline
\end{tabular}

aerosol water from calculating total particle masses of particles (i.e., we use dry mass to define the mass fractions in Table 1). Note that from the information on per-particle composition, it is straightforward to calculate per-particle properties, such as hygroscopicity (Riemer et al., 2010; Zaveri et al., 2010; Ching et al., 2012; Tian et al., 2013), optical properties (Zaveri et al., 2010), or particle reactivity (Kaiser et al., 2011).

\subsection{Single-process case descriptions}

The following model setup applies to the cases listed in Table 6 . The simulation time was $24 \mathrm{~h}$, and $10^{5}$ computational particles were used to initialize the simulations. To simplify the interpretation of the results, we applied a flat weighting function in the sense of DeVille et al. (2011). The temperature was $288.15 \mathrm{~K}$, the pressure was $10^{5} \mathrm{~Pa}$, the mixing height of the box was $300 \mathrm{~m}$, and the relative humidity (RH) was 0.7. Dilution with background air was not simulated. Each initial monodisperse mode was defined by an initial 
Table 6. List of single-process case studies. Column "Chem." indicates if gas and aerosol phase chemistry were simulated, and column "Coag." indicates if coagulation was simulated.

\begin{tabular}{|c|c|c|c|c|c|c|}
\hline Case & Aerosol initial & Aerosol emissions & Chem. & Coag. & $D_{\alpha}$ & $\chi$ \\
\hline 1 & $\begin{array}{l}1 \text { monodisperse mode } \\
73 \% \mathrm{SO}_{4}, 27 \% \mathrm{NH}_{4}, D_{i}=1.8\end{array}$ & $\begin{array}{l}\text { monodisperse } \\
100 \% \mathrm{BC}, D_{i}=1\end{array}$ & No & No & decr. & decr. \\
\hline 2 & $\begin{array}{l}2 \text { monodisperse modes } \\
\text { (1) } 50 \% \mathrm{SO}_{4}, 50 \% \text { OIN, } D_{i}=2 \\
\text { (2) } 50 \% \mathrm{BC}, 50 \% \mathrm{OC}, D_{i}=2\end{array}$ & $\begin{array}{l}\text { monodisperse } \\
50 \% \text { OC, } 50 \% \mathrm{BC}, D_{i}=2\end{array}$ & No & No & const. & incr. \\
\hline 3 & $\begin{array}{l}1 \text { monodisperse mode } \\
100 \% \mathrm{BC}, D_{i}=1\end{array}$ & $\begin{array}{l}\text { monodisperse } \\
73 \% \mathrm{SO}_{4}, 27 \% \mathrm{NH}_{4}, D_{i}=1.8\end{array}$ & No & No & incr. & incr. \\
\hline 4 & $\begin{array}{l}2 \text { monodisperse modes } \\
\text { (1) } 100 \% \mathrm{BC}, D_{i}=1 \\
\text { (2) } 100 \% \mathrm{SO}_{4}, D_{i}=1\end{array}$ & No & No & Yes & incr. & incr. \\
\hline 5 & $\begin{array}{l}1 \text { monodisperse mode } \\
100 \% \mathrm{BC}, D_{i}=1\end{array}$ & No & Yes & No & incr. & $100 \%$ \\
\hline 6 & $\begin{array}{l}1 \text { monodisperse mode } \\
37 \% \mathrm{BC}, 16 \% \mathrm{SO}_{4}, 16 \% \mathrm{NH}_{4}, 32 \% \mathrm{NO}_{3}, \\
D_{i}=3.7\end{array}$ & No & Yes & No & decr. & $100 \%$ \\
\hline 7 & $\begin{array}{l}2 \text { monodisperse modes } \\
\text { (1) } 65 \% \mathrm{SO}_{4}, 24 \% \mathrm{NH}_{4}, 10 \% \mathrm{BC}, D_{i}=2.35 \\
\text { (2) } 7 \% \mathrm{SO}_{4}, 3 \% \mathrm{NH}_{4}, 90 \% \mathrm{BC}, D_{i}=1.5\end{array}$ & No & Yes & No & incr. & incr. \\
\hline 8 & $\begin{array}{l}2 \text { monodisperse modes } \\
\text { (1) } 92 \% \mathrm{BC}, 2 \% \mathrm{NH}_{4}, 6 \% \mathrm{NO}_{3}, D_{i}=1.4 \\
\text { (2) } 89.3 \% \mathrm{BC}, 7.2 \% \mathrm{SO}_{4}, 2.8 \% \mathrm{NH}_{4}, 0.3 \% \\
\mathrm{NO}_{3}, D_{i}=1.6\end{array}$ & No & Yes & No & incr. & decr. \\
\hline
\end{tabular}

total number concentration of $N_{\text {tot }}=3 \times 10^{7} \mathrm{~m}^{-3}$ and by an initial diameter of $D=0.1 \mu \mathrm{m}$.

For the cases that included particle emissions (Cases 1, 2 , and 3), the diameter of the emitted particles was $D=$ $0.1 \mu \mathrm{m}$. The emitted particle flux was $E=5 \times 10^{7} \mathrm{~m}^{-2} \mathrm{~s}^{-1}$ for Case 1, E = 1.6 $\times 10^{10} \mathrm{~m}^{-2} \mathrm{~s}^{-1}$ for Case 2, and $E=$ $1.6 \times 10^{8} \mathrm{~m}^{-2} \mathrm{~s}^{-1}$ for Case 3. For the cases that included chemistry (Cases 5, 6, 7, and 8), the initial conditions for the gas phase were $50 \mathrm{ppb} \mathrm{O}_{3}, 4 \mathrm{ppbNH}_{3}$ and $1 \mathrm{ppb} \mathrm{HNO}_{3}$. The gas phase emissions of $\mathrm{NO}$ and $\mathrm{NH}_{3}$ were prescribed at a constant rate of $60 \mathrm{nmol} \mathrm{m}^{-2} \mathrm{~s}^{-1}$ and $9 \mathrm{nmol} \mathrm{m}^{-2} \mathrm{~s}^{-1}$, respectively. Photolysis rates were constant, corresponding to a solar zenith angle of $0^{\circ}$. Coagulation was not simulated except for Case 4.

The results from the single-process studies are summarized in Figs. 3, 4, and 5. The left column of Figs. 3 and 4 shows time series of the per-particle species diversity distribution, $n\left(t, D_{i}\right)$. The right column in these figures shows the time series of the average per-particle diversity $D_{\alpha}$, the population diversity $D_{\gamma}$, and the corresponding mixing state index $\chi$. Each simulation is also depicted in the mixing state diagram in Fig. 5. The next sections discuss the main features of these results.

\subsection{Emission cases (Cases 1, 2, and 3)}

Cases 1, 2, and 3 explore the impact of particle emissions into a pre-existing aerosol population. In these cases coagulation

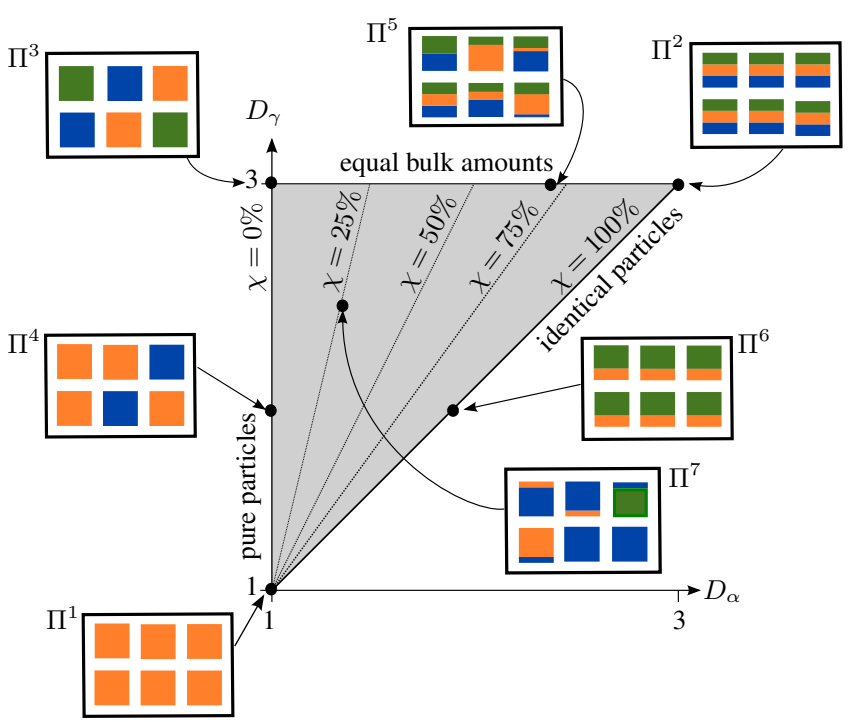

Fig. 2. Mixing state diagram to illustrate the relationship between per-particle diversity $D_{\alpha}$, bulk diversity $D_{\gamma}$, and mixing state index $\chi$ for representative aerosol populations, as listed in Table 4. See Section 2 and Table 3 for more details.

and condensation were not simulated. Depending on the relative magnitudes of the per-particle diversities of the emitted versus the pre-exisiting particles, emissions can have different impacts on the aerosol mixing state. 

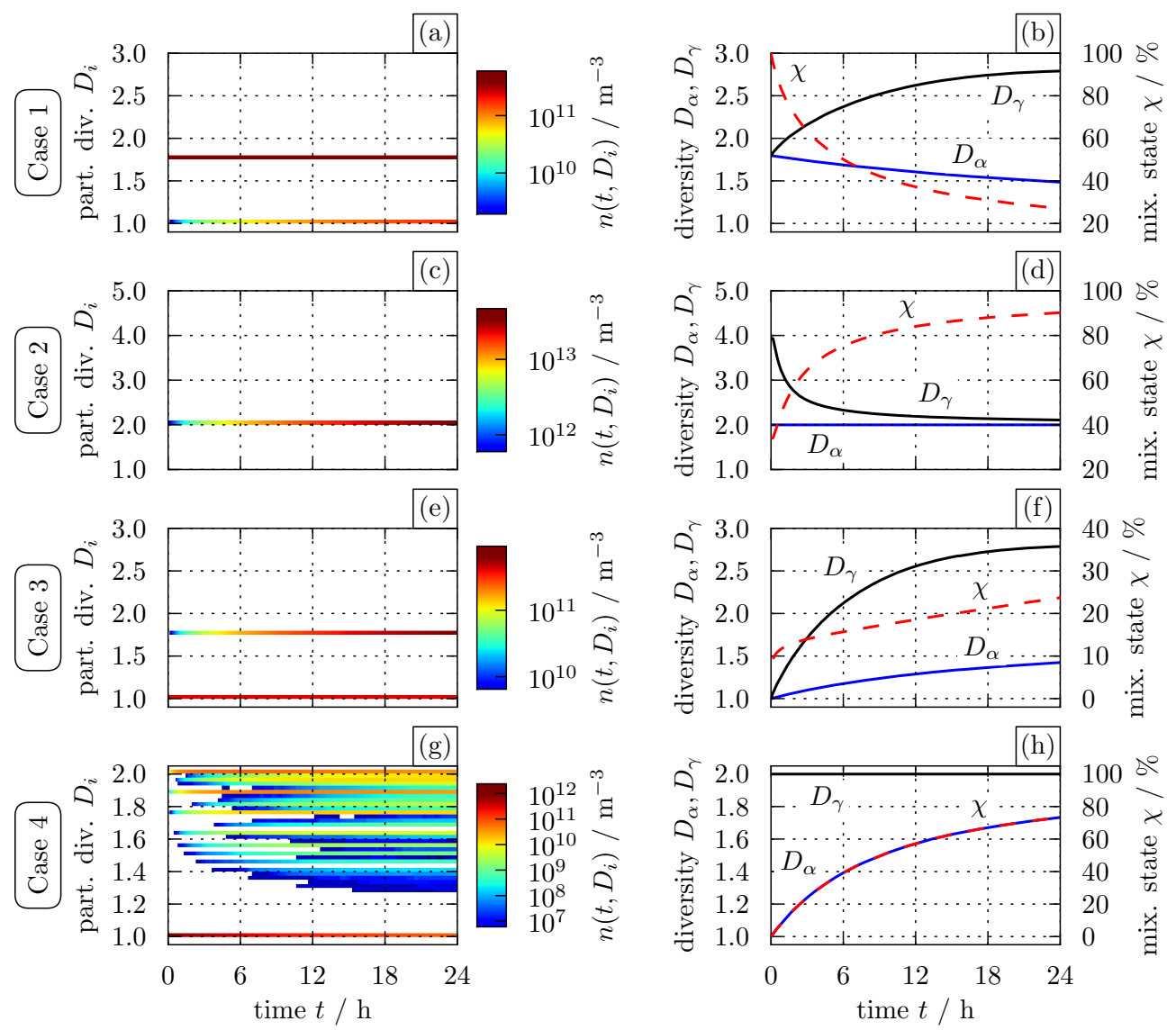

Fig. 3. Diversity and mixing state evolution for archetypal cases. Left column: Distributions of per-particle diversity $D_{i}$ as a function of time. Right column: time series of average particle diversity $D_{\alpha}$, population diversity $D_{\gamma}$, and the mixing state index $\chi$. Note that the left axis shows $D_{\alpha}$ and $D_{\gamma}$, and the right axis shows $\chi$. The rows correspond to Cases 1 to 4 as defined in Table 6 .

- Case 1: we considered an initial particle population that contained ammonium sulfate $\left(D_{i}=1.8\right.$ effective species) combined with emissions of pure $\mathrm{BC}$ particles ( $D_{i}=1$ effective species). This process is shown in Fig. 3a with the number concentration of the ammonium sulfate particles remaining constant, and the number concentration of the emitted BC particles increasing over time. Due to the emission of particles with lower $D_{i}$ than the initial population, the average per-particle diversity $D_{\alpha}$ decreased (Fig. 3b). On the other hand, adding particles of a different species than the initial particles increased the population species diversity $D_{\gamma}$. This results in a decreasing mixing state index $\chi$ and is consistent with the particles becoming on average more simple, and the population more inhomogeneous. In this particular case the population evolved from $100 \%$ internally mixed $(\chi=1)$ to $30 \%$ internally mixed $(\chi=0.3)$. The blue solid line in Fig. 5 shows this process on the mixing state diagram.

- Case 2: we prescribed an initial particle population of two monodisperse modes, with mode 1 consisting of mineral dust (model species OIN, "other inorganics") and $\mathrm{SO}_{4}$, and mode 2 consisting of $\mathrm{BC}$ and OC. Since all particles contained two species in equal amounts, $D_{i}=2$ for all particles. The emissions consisted of mode-2 particles. Since the $D_{i}$-values of all particles were identical, we only observe one line in Fig. 3c, and the average per-particle species diversity $D_{\alpha}$ in Fig. $3 \mathrm{~d}$ was constant with time. However, since the emitted particles had the same composition as one of the initial modes, $D_{\gamma}$ decreased in this simulation, hence the mixing state index $\chi$ increased from $33 \%$ to $90 \%$ internally mixed. This is an example of a process where the average diversity on a particle-level did not change, but on a population-level diversity decreased. The blue dashed line in Fig. 5 shows this process on the mixing state diagram.

- Case 3: we considered an initial particle population of pure BC particles ( $D_{i}=1$ effective species) combined with emissions of particles containing ammonium sulfate ( $D_{i}=1.8$ effective species) (Fig. 3e). This case represents the opposite of Case 1. The emission of 

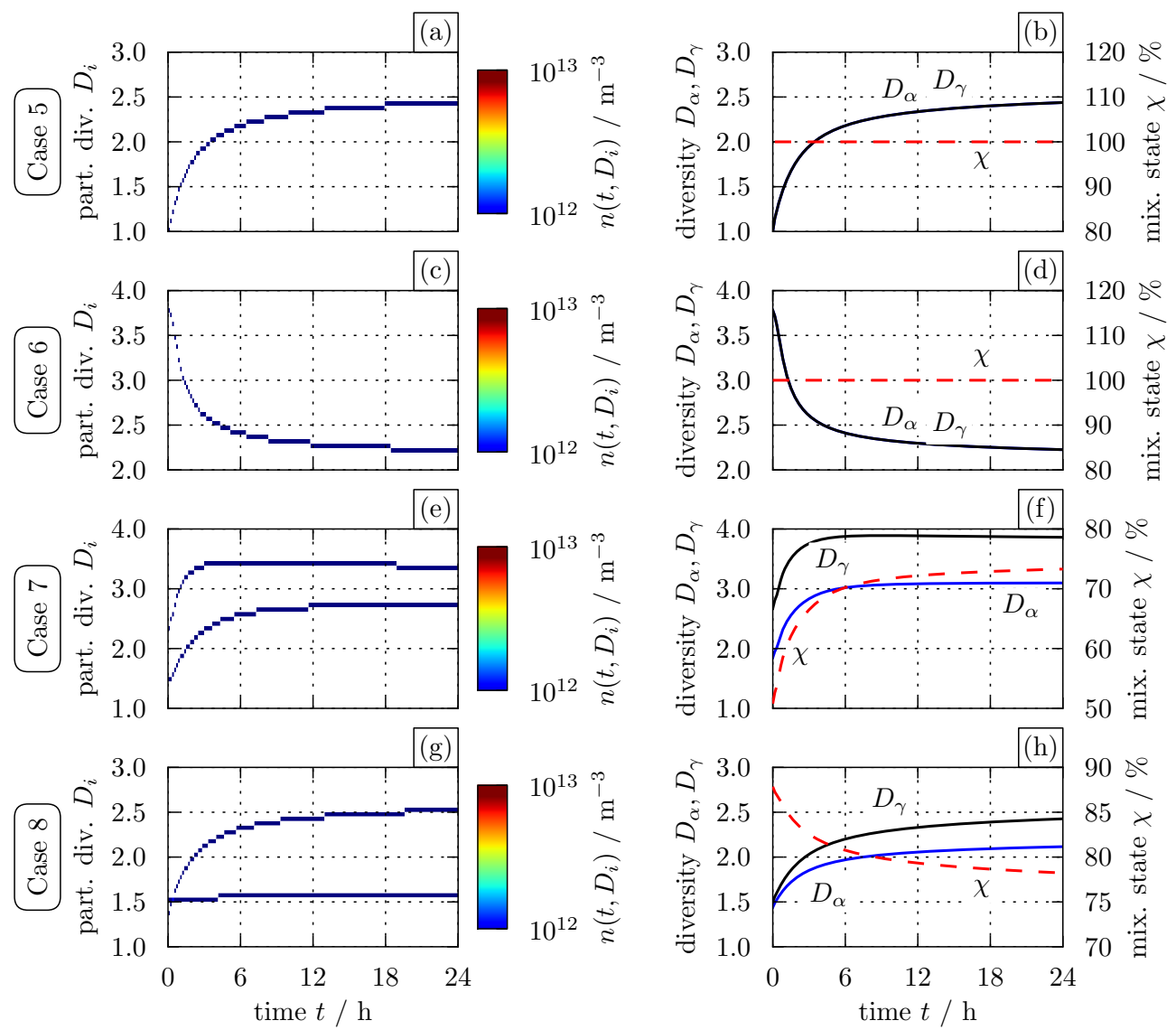

Fig. 4. Diversity and mixing state evolution for archetypal cases. Left column: distributions of per-particle diversity $D_{i}$ as a function of time. Right column: time series of average particle diversity $D_{\alpha}$, population diversity $D_{\gamma}$, and the mixing state index $\chi$. Note that the left axis shows $D_{\alpha}$ and $D_{\gamma}$, and the right axis shows $\chi$. The rows correspond to Cases 5 to 8 as defined in Table 6 .

mixed particles with a higher per-particle diversity than that of the initial particles increased $D_{\alpha}$, as the particles became more diverse on average. At the same time population diversity $D_{\gamma}$ also increased. As a result the mixing state index $\chi$ increased, indicating that the population became more homogeneous (Fig. 3e). The cyan line in Fig. 5 shows this process on the mixing state diagram.

\subsection{Coagulation case (Case 4)}

Case 4 explores the impact of coagulation. Emissions and condensation were not simulated. We considered an initial particle population that contained a subpopulation of pure $\mathrm{BC}$ particles and another subpopulation of pure $\mathrm{SO}_{4}$, giving $D_{i}=1$ effective species for all particles at the start of the simulation. Coagulation of the particles produced mixed particles with $1 \leq D_{i} \leq 2$, as Fig. $3 \mathrm{~g}$ shows. The largest possible value for $D_{i}$ was 2 effective species, resulting from coagulation events that led to equal amounts of $\mathrm{SO}_{4}$ and $\mathrm{BC}$ in the particles. Values of $D_{i}$ smaller than 2 developed as a result of multiple coagulation events, when one species dominated the composition of the constituent particles. Since coagulation produced mixed particles, $D_{\alpha}$ increased, indicating that particles became more complex on average. In contrast, as stated in Theorem 2, the population diversity $D_{\gamma}$ remained constant, as shown in Fig. $3 \mathrm{~h}$. As a result $\chi$ increased from $0 \%$ to about $75 \%$ internally mixed, indicating that the population became more homogeneous. The red line in Fig. 5 shows this process on the mixing state diagram. Since in this scenario the bulk amounts of $\mathrm{SO}_{4}$ and $\mathrm{BC}$ were equal, this line traces the upper edge of the triangle in the mixing state diagram.

\subsection{Condensation cases (Cases 5-8)}

Cases 5-8 explore the impact of condensation. In these cases particle emissions and coagulation were not simulated. Since we only prescribed gas phase emissions of $\mathrm{NO}$ and $\mathrm{NH}_{3}$, only ammonium nitrate formed as a secondary species. Similar to the emission cases, the condensation cases illustrate that the same process (here condensation) can lead to different outcomes in terms of mixing state, depending on the conditions of the scenario. As we will demonstrate below, on a 
Table 7. Initial, background, and emission aerosol populations for the urban plume case, giving the number concentration $N_{\mathrm{a}}$ or area rate of emission $E_{\mathrm{a}}$ as appropriate. The aerosol population size distributions are log-normal and defined by the geometric mean diameter $D_{\mathrm{g}}$ and the geometric standard deviation $\sigma_{\mathrm{g}}$.

\begin{tabular}{llllll}
\hline Initial/background & $N_{\mathrm{a}} / \mathrm{cm}^{-3}$ & $D_{\mathrm{g}} / \mu \mathrm{m}$ & $\sigma_{\mathrm{g}}$ & Composition by mass & $D_{i}$ \\
\hline Aitken mode & 1800 & 0.02 & 1.45 & $50 \%\left(\mathrm{NH}_{4}\right)_{2} \mathrm{SO}_{4}+50 \% \mathrm{SOA}$ & 2.7 \\
Accumulation model & 1500 & 0.116 & 1.65 & $50 \%\left(\mathrm{NH}_{4}\right)_{2} \mathrm{SO}_{4}+50 \% \mathrm{SOA}$ & 2.7 \\
\hline Emission & $E_{\mathrm{a}} / \mathrm{m}^{-2} \mathrm{~s}^{-1}$ & $D_{\mathrm{g}} / \mu \mathrm{m}$ & $\sigma_{\mathrm{g}}$ & Composition by mass & $D_{i}$ \\
\hline Meat cooking & $9 \times 10^{6}$ & 0.086 & 1.91 & $100 \% \mathrm{POA}$ & 1 \\
Diesel vehicles & $1.6 \times 10^{8}$ & 0.05 & 1.74 & $30 \% \mathrm{POA}+70 \% \mathrm{BC}$ & 1.8 \\
Gasoline vehicles & $5 \times 10^{7}$ & 0.05 & 1.74 & $80 \% \mathrm{POA}+20 \% \mathrm{BC}$ & 1.7 \\
\hline
\end{tabular}

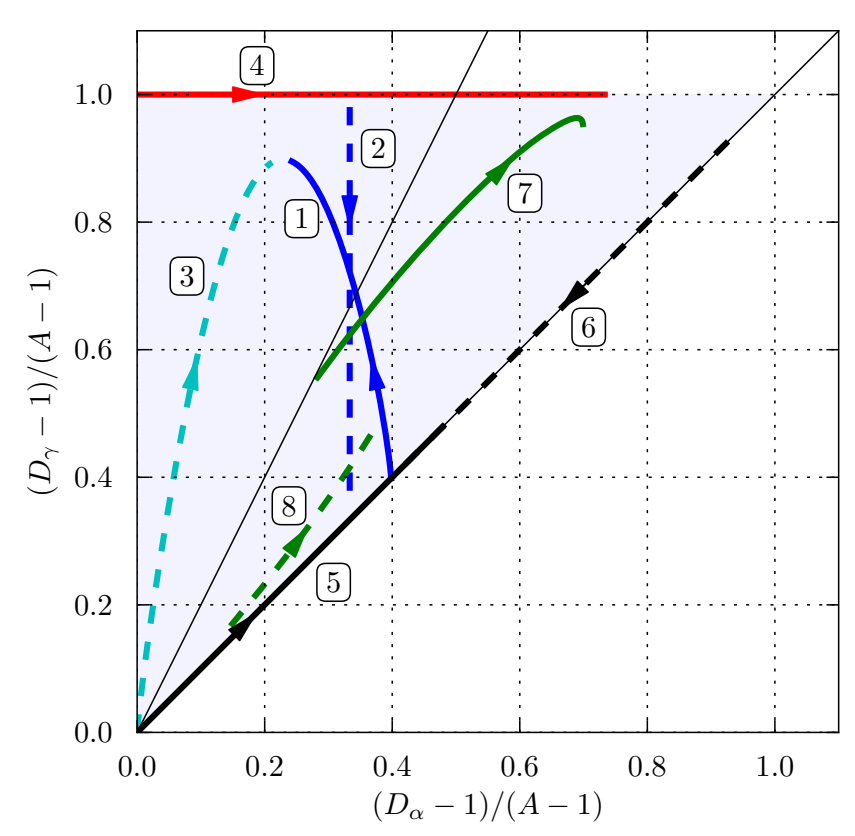

Fig. 5. Mixing state diagram showing the normalized population species diversity $D_{\gamma}$ versus the normalized average particle species diversity $D_{\alpha}$ for all single-process cases. The number labels refer to the cases defined in Table 6 and shown in Figs. 3 and 4.

population level, condensation can produce either more homogeneous or less homogeneous populations, and on a particle level, it can produce either less diverse or more diverse particles.

- Case 5: we considered an initial monodisperse particle population of pure BC particles, hence $D_{i}$ was initially 1 (Fig. 4a). Over the course of the simulation, secondary ammonium nitrate formed on the particles, with the same amount on each particle. Therefore $D_{\alpha}$ increased and was at all times equal to $D_{\gamma}$. This resulted in a constant value $\chi=1$, as shown in Fig. 4b. While the population was always $100 \%$ internally mixed, the increase of $D_{\alpha}$ and $D_{\gamma}$ can be interpreted as an increase in diversity both on a per-particle level and on a population level. This process is represented by the black solid line in the mixing state diagram (Fig. 5).

- Case 6: here we initialized each particle with a mixture of $\mathrm{BC}$, ammonium sulfate and ammonium nitrate, so the particles started out with $D_{i}=3.7 \mathrm{effec}$ tive species (Fig. 4c). The formation of secondary ammonium nitrate led to a decrease of $D_{\alpha}$, again with $\chi=1$ at all times for a $100 \%$ internally mixed population (Fig. 4d). The decrease of $D_{\alpha}$ and $D_{\gamma}$ can be interpreted as a decrease in the complexity of the particles. This is consistent with the particle composition becoming more dominated by the condensing species. This process is represented by the black dashed line in the mixing state diagram (Fig. 5).

- Case 7: we initialized the population with two monodisperse modes. One consisted predominantly of BC with some ammonium sulfate $\left(D_{i}=1.5\right.$ effective species). The other was mainly ammonium sulfate with a small amount of BC $\left(D_{i}=2.35\right.$ effective species). The condensation of ammonium nitrate on all particles led to increasing $D_{i}$ for each subpopulation (Fig. 4e). Ammonium nitrate condensed on all particles, hence the overall population became more homogeneous, indicated by increasing $\chi$ from $50 \%$ to about $75 \%$ internally mixed (Fig. 4f). This process is represented by the green solid line in the mixing state diagram (Fig. 5).

- Case 8: we initialized the population with two monodisperse modes. They both consisted predominantly of BC, but differed in their composition of inorganic species (see Table 6) and contained 1.4 and 1.6 effective species, respectively. This case was designed so that differences would occur in the ammonium nitrate formation on the two modes based on differences in aerosol water content (Fig. 4g). The result was that the two subpopulations diverged from each other in composition. While $D_{\alpha}$ increased, $D_{\gamma}$ increased even 

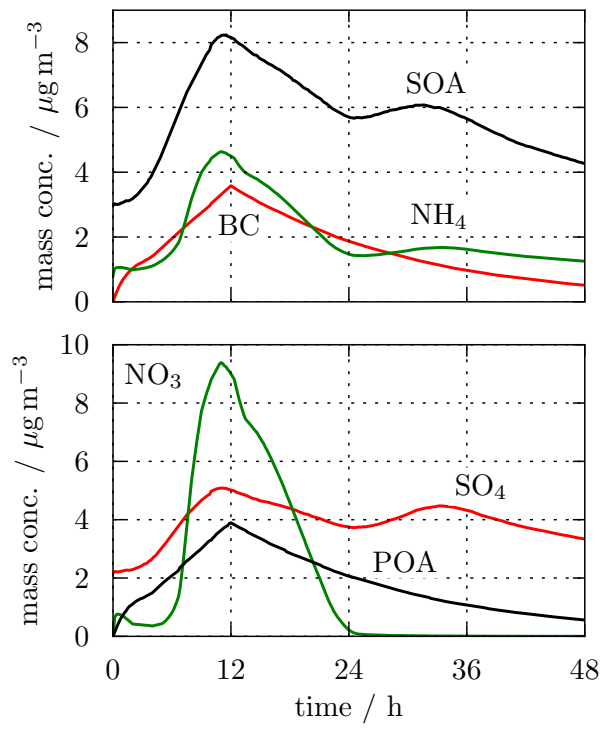

Fig. 6. Evolution of bulk aerosol species for the urban plume case.

faster, hence $\chi$ decreased (Fig. 4h) from $90 \%$ to $78 \%$ internally mixed. In this case ammonium nitrate condensed preferentially on one of the two subpopulations, hence condensation caused the overall population to be more inhomogeneous. This process is represented by the green dashed line in the mixing state diagram (Fig. 5).

\section{Complex urban plume simulation}

\subsection{Overview of urban plume case}

In this section we discuss the case of a more complex urban plume scenario. The details of this scenario are described in Zaveri et al. (2010) and Ching et al. (2012). We assumed that a Lagrangian air parcel containing background air was advected within the mixed layer across a large urban area. The start of the simulation was at 06:00 LT in the morning. During the first $12 \mathrm{~h}$ of simulation, while the air parcel traveled over the urban area, we prescribed continuous gas emissions $\mathrm{NO}_{\mathrm{x}}, \mathrm{SO}_{2}, \mathrm{CO}$, and volatile organic compounds (VOCs), as well as emissions of three different particle types, which originated from gasoline engines, diesel engines, and meat-cooking activities. The specifics of the particle emissions and the initial particle distributions, here initialized as log-normal distributions, are listed in Table 7 . We slightly modified two details of the original urban plume case presented in Zaveri et al. (2010). The initial and background particles of the urban plume case in Zaveri et al. (2010) contained small amounts of BC. Here we changed this, so that these particle types only contained ammonium sulfate and SOA, while BC is exclusively associated with particle emissions. We also set the initial concentration of $\mathrm{HCl}$ to zero.
Both of these modifications simplify the discussion in this section.

Unlike the single-process cases presented in Sect. 3, this urban plume case included diurnal variations of the meteorological variables (temperature, relative humidity, mixing height and solar zenith angle). Dilution with background air occured during the entire simulation period, and gas and aerosol chemistry as well as coagulation amongst the particles modified the aerosol population further. For reference we show the bulk time series of the aerosol species in Fig. 6 . The $\mathrm{BC}$ and POA mass concentration increased during the emission phase, and decreased thereafter due to dilution with the background. The time series of the secondary aerosol species sulfate and SOA were determined by the interplay between loss by dilution and photochemical production. The ammonium nitrate mass concentration depended on the gas concentrations of its precursors, $\mathrm{HNO}_{3}$ and $\mathrm{NH}_{3}$. When the two gas precursors were abundant during the emission phase, ammonium nitrate formed rapidly. After emissions and photochemistry ceased, $\mathrm{HNO}_{3}$ and $\mathrm{NH}_{3}$ decreased due to dilution, and the ammonium nitrate evaporated.

\subsection{Evolution of mixing state for urban plume case}

To analyze the mixing state evolution for the urban plume case, we graph the same quantities as for the single-process cases. We show two versions of this analysis, first we only include the subpopulation of BC-containing particles in Fig. 7, and then we include the whole population in Fig. 8.

Focusing on the BC-containing particles, Fig. 7a shows that the particle diversity values $D_{i}$ covered a wide range at any point in time during the simulation, and this range changed over the course of the simulation. To explain this, we refer to Table 7, which lists the initial particle diversity values of the different particle types. Particles originating from diesel engine emissions and gasoline engine emissions entered the simulation with $D_{i}=1.8$ effective species and $D_{i}=1.7$ effective species, respectively. However, coagulation and, more importantly, condensation altered these initial values quickly. Given the particular mix of gas precursor emissions, the number of secondary species in this simulation was 8 , and adding the primary species $\mathrm{BC}$ and POA, the total number of species is 10 , which is the maximum number of effective species for this simulation. Indeed, as shown in Fig. 7a, many particles during the first $12 \mathrm{~h}$ of simulation acquired diversity values of up to 9 effective species. At the same time, due to fresh emissions, particles with lower particle diversity values were replenished, which maintained the spread of $D_{i}$ values during the emission period. During the emission phase we also observe BC-containing particles with $D_{i}$ values lower than their initial value of 1.7 or 1.8 effective species. These arose due to coagulation with meat cooking aerosol particles with $D_{i}=1$ (see Table 7). After the emission period, and especially on the second day, the majority of particles resided in a narrow range of $D_{i}$ values between 6 

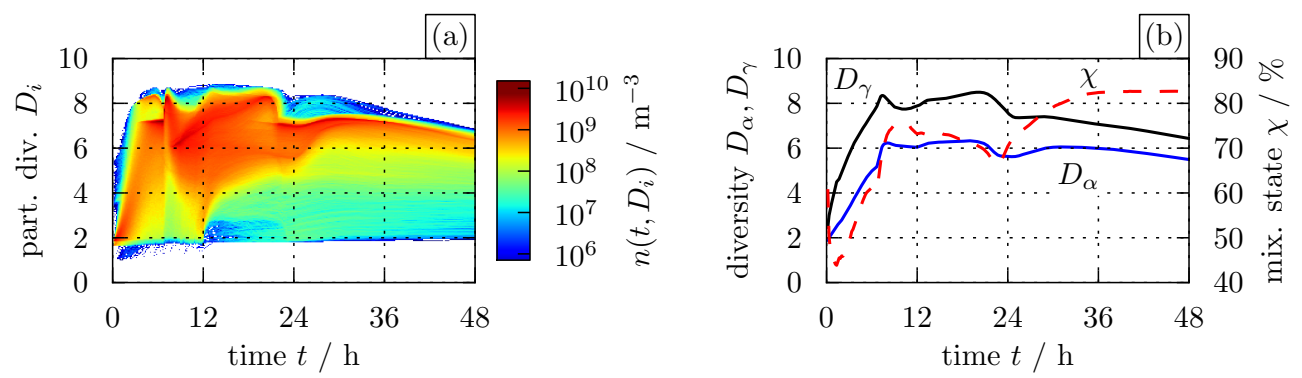

Fig. 7. Diversity and mixing state evolution for BC-containing particles in the urban plume case. (a) Distribution of per-particle diversity $D_{i}$ as a function of time. (b) Time series of average particle diversity $D_{\alpha}$, population diversity $D_{\gamma}$, and the mixing state index $\chi$.
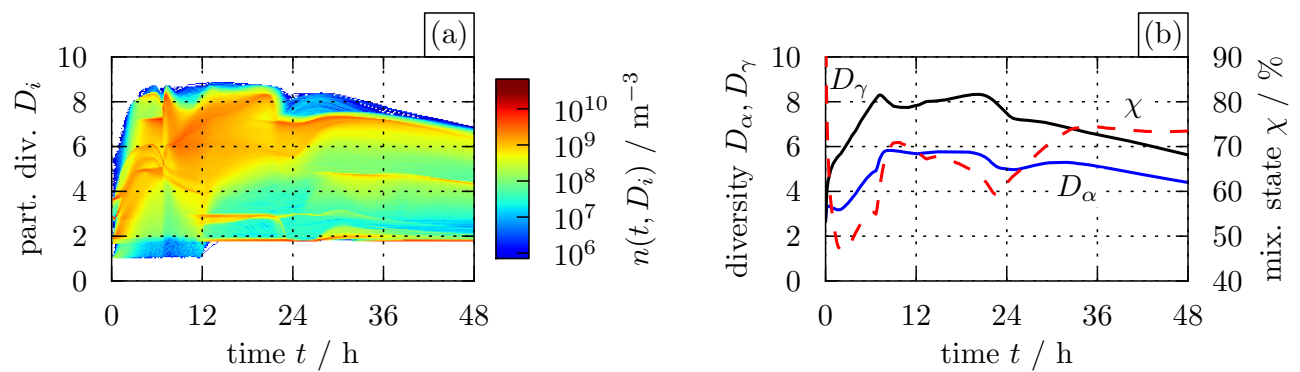

Fig. 8. Diversity and mixing state evolution for all particles in the urban plume case. (a) Distribution of per-particle diversity $D_{i}$ as a function of time. (b) Time series of average particle diversity $D_{\alpha}$, population diversity $D_{\gamma}$, and the mixing state index $\chi$.

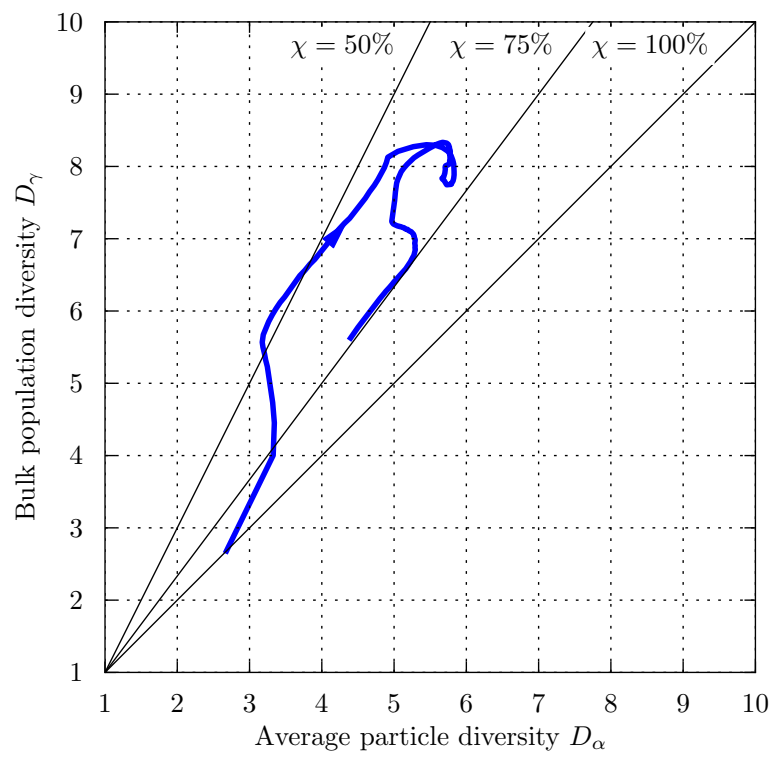

Fig. 9. Mixing state diagram for urban plume case showing the population species diversity $D_{\gamma}$ versus the average particle species diversity $D_{\alpha}$ for the urban plume case presented in Fig. 8 (all particles included).

and 7 effective species. This is consistent with our notion of "aging", which results in a less diverse population. However it is interesting to note that at all times a range of particles still existed with lower number of effective species.

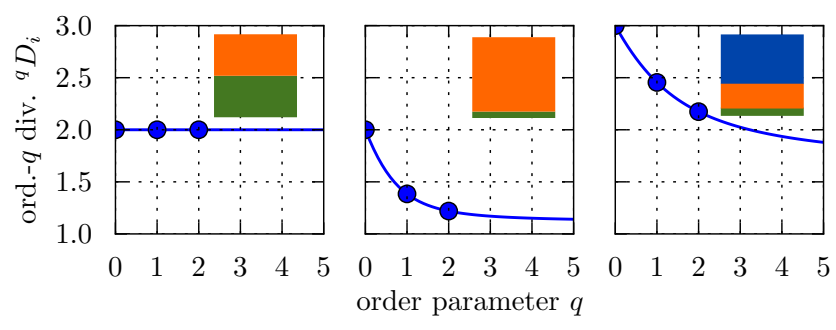

Fig. 10. Generalized per-particle diversity ${ }^{q} D_{i}$ of order $q$ for varying $q$, shown for three different particles (inset square plots). Left: a particle with equal amounts of two species. Center: a particle with two species in unequal amounts. Right: a particle with three species in unequal amounts. The order $q$ controls the importance of species with small mass fraction. When $q=0$ all species are taken to be equally present, irrespective of mass fraction, so ${ }^{0} D_{i}$ is simply the number of species present in the particle. When $q=1$ the generalized diversity is equal to the regular diversity defined from the Shannon entropy in Sect. 2. When $q=2$ the generalized diversity ${ }^{2} D_{i}$ is the inverse of the Simpson index $\lambda_{i}=\sum_{a=1}^{A}\left(p_{i}^{a}\right)^{2}$ for particle $i$ (Simpson, 1949), often used in the form of the Gini-Simpson index $1-\lambda_{i}$ (Peet, 1974; Jost, 2006).

Figure $7 \mathrm{~b}$ shows the corresponding evolution of $D_{\alpha}, D_{\gamma}$, and $\chi$. The average particle diversity $D_{\alpha}$ displayed a rapid increase during the condensation period of the first $6 \mathrm{~h}$ of simulation, consistent with the BC-containing particles becoming more complex in composition as condensation and coagulation were at work. After this, $D_{\alpha}$ stayed essentially 
constant, with small modulations induced by the diurnal cycle of evaporation and condensation of secondary material. The importance of condensation is also reflected by the increase in the bulk population diversity $D_{\gamma}$. The mixing state index $\chi$ decreased from $70 \%$ to $50 \%$ internally mixed during the first two hours because of the effect of meat cooking aerosol emissions; some of these particles coagulated with the $\mathrm{BC}$-containing particles, making the subpopulation of $\mathrm{BC}$-containing particles more heterogeneous. During the period of secondary aerosol formation on the first day $(t=2-$ $11 \mathrm{~h}), \chi$ increased to $75 \%$ internally mixed, which means that the population of $\mathrm{BC}$-containing particles became more homogeneous during that time. After another day of processing the aerosol in the air parcel, without fresh emissions, the simulation period ended with the aerosol population being $82 \%$ internally mixed.

The same analysis performed for all particles reveals a qualitatively similar pattern for the distributions of $D_{i}$ and the time series of $D_{\alpha}, D_{\gamma}$, and $\chi$, with some differences in the details, as shown in Fig. 8. For example, during the first $12 \mathrm{~h}$, when emissions were present, the minimum value of the per-particle diversities was $D_{i}=1$ effective species, due to the meat cooking particle emissions (Fig. 8a). The red line at $D_{i}=1.8$ in Fig. 8a can be attributed to background particles from which SOA components had evaporated once they entered the air parcel, hence ammonium sulfate particles remained. The values for $\chi$ from $2 \mathrm{~h}$ of simulation onwards was lower when considering the whole population, compared to $\chi$ of the subpopulation of BC-containing particles. This makes sense, since including all particle types allows for a more heterogeneous population. Figure 9 shows the mixing state diagram that corresponds to the urban plume case shown in Fig. 8. At the end of the two-day simulation period the whole population was $75 \%$ internally mixed.

\section{Conclusions}

With the advent of sophisticated measurement techniques on a single-particle level, a wealth of information about the composition of an aerosol population has become available. The observations show that, on a particle level, aerosols are complex mixtures of many species, and different particle types can coexist within one population. This reflects the particles' sources as well as their history during the transport in the atmosphere. To describe this distribution of per-particle compositions the term "mixing state" has been coined; however, so far this term has not been rigorously defined and no concept existed to quantify it.

This paper, for the first time, presents a framework for quantifying the mixing state of aerosol particle populations. In developing this framework we borrowed the idea of entropy-derived "diversity parameters" from other disciplines, allowing us to define the per-particle species diversity
$D_{i}$, the average particle diversity $D_{\alpha}$, the population diversity $D_{\gamma}$, and the mixing state index $\chi$.

The average particle diversity $D_{\alpha}$ is a measure for the number of effective species on a per-particle level, while $D_{\gamma}$ quantifies the number of effective species of the bulk population. An affine ratio of the two, represented by the mixing state index $\chi$, measures how close the population is to an external or internal mixture.

Using particle-resolved simulations to illustrate the evolution of the mixing state metrics for selected test cases revealed the following results. Coagulation always increases the degree of internal mixture. The impact of emission and condensation on mixing state is not as straightforward, and in Sect. 3 we showed examples of scenarios where $\chi$ increased, decreased or stayed constant as a result of emissions or condensation. However, in the case of emissions, perhaps the most intuitive scenario is where "fresh" particles (low $D_{i}$ ) are emitted into an "aged" population (high $D_{i}$ ) which decreases the degree of internal mixture and is reflected by decreasing $\chi$. Similarly, in the case of condensation, the most intuitive case is where the same species condenses on all particles of an initially low- $\chi$ population, increasing the mixing state index, consistent with our notion of "aging" as a process that increases the degree of internal mixing.

We expect that the mixing state index $\chi$ will prove useful in communicating, discussing, and categorizing the aerosol mixing state of both observed and modeled aerosol populations. This, in turn, will facilitate answering the key research questions: (1) what is the mixing state at emission and how does it evolve in the atmosphere; (2) what is the impact of mixing state on climate-related and health-relevant aerosol properties; and (3) to what extent do models need to account for mixing state to answer these questions? In this context, it would be very useful to obtain quantitative information on per-particle composition from field observations and laboratory experiments, together with measurements of application-relevant bulk properties.

\section{Appendix A}

\section{Generalized entropy and generalized diversity}

The mixing entropy can be generalized to give more or less importance to species with small mass fractions. This generalization was originally due to Havrda and Charvát (1967) and then was independently rediscovered at least three times: in information theory (Daróczy, 1970; Aczél and Daróczy, 1975), in ecology (Patil and Taillie, 1979, 1982), and in physics (Tsallis, 1988, 2009). In the physics literature this generalized entropy is frequently called the Tsallis entropy or the HCDT (Havrda-Charvát-Daróczy-Tsallis) entropy. 
The per-particle generalized entropy of order $q \geq 0$ is denoted ${ }^{q} H_{i}$ and leads to generalized average mixing entropy ${ }^{q} H_{\alpha}$ and generalized population bulk entropy ${ }^{q} H_{\gamma}$. These are defined by

$$
{ }^{q} H_{i}= \begin{cases}\left|\left\{a: p_{i}^{a}>0, a=1, \ldots, A\right\}\right|-1 & \text { if } q=0 \\ -\sum_{a=1}^{A} p_{i}^{a} \ln p_{i}^{a} & \text { if } q=1 \\ \frac{1}{q-1}\left(1-\sum_{a=1}^{A}\left(p_{i}^{a}\right)^{q}\right) & \text { if } q \notin\{0,1\}\end{cases}
$$

${ }^{q} H_{\alpha}=\sum_{i=1}^{N} p_{i}{ }^{q} H_{i}$

${ }^{q} H_{\gamma}= \begin{cases}\left|\left\{a: p^{a}>0, a=1, \ldots, A\right\}\right|-1 & \text { if } q=0 \\ -\sum_{a=1}^{A} p^{a} \ln p^{a} & \text { if } q=1 \\ \frac{1}{q-1}\left(1-\sum_{a=1}^{A}\left(p^{a}\right)^{q}\right) & \text { if } q \notin\{0,1\} .\end{cases}$

Note that for $q=0$ the definition of ${ }^{0} H_{i}$ is one less than the number of species present in particle $i$. The special cases of $q=0$ and $q=1$ are such that the generalized entropy is continuous in $q$. To convert a generalized entropy of order $q$ to a corresponding generalized diversity, the conversion function ${ }^{q} f$ is defined by

$$
\begin{aligned}
{ }^{q} f\left({ }^{q} H\right) & = \begin{cases}e^{q} H & \text { if } q=1 \\
\left(1-(q-1)^{q} H\right)^{1 /(1-q)} & \text { if } q \neq 1\end{cases} \\
\operatorname{dom}^{q} f & = \begin{cases}{[0, \infty)} & \text { if } q \leq 1 \\
{\left[0, \frac{1}{q-1}\right)} & \text { if } q>1,\end{cases}
\end{aligned}
$$

where the domain of ${ }^{q} f$ is as given.

The generalized diversities of order $q$ are now defined by

$$
{ }^{q} D_{i}={ }^{q} f\left({ }^{q} H_{i}\right)= \begin{cases}\left|\left\{a: p_{i}^{a}>0, a=1, \ldots, A\right\}\right| & \text { if } q=0 \\ \prod_{a=1}^{A}\left(p_{i}^{a}\right)^{-p_{i}^{a}} & \text { if } q=1 \\ \left(\sum_{a=1}^{A}\left(p_{i}^{a}\right)^{q}\right)^{1 /(1-q)} & \text { if } q \notin\{0,1\}\end{cases}
$$

${ }^{q} D_{\alpha}={ }^{q} f\left({ }^{q} H_{\alpha}\right)= \begin{cases}\prod_{i=1}^{N}\left(D_{i}\right) p_{i} & \text { if } q=1 \\ \left(\sum_{i=1}^{N} p_{i}\left({ }^{q} D_{i}\right)^{1-q}\right)^{1 /(1-q)} & \text { if } q \neq 1\end{cases}$

${ }^{q} D_{\gamma}={ }^{q} f\left({ }^{q} H_{\gamma}\right)= \begin{cases}\left|\left\{a: p^{a}>0, a=1, \ldots, A\right\}\right| & \text { if } q=0 \\ \prod_{a=1}^{A}\left(p^{a}\right)^{-p^{a}} & \text { if } q=1 \\ \left(\sum_{a=1}^{A}\left(p^{a}\right)^{q}\right)^{1 /(1-q)} & \text { if } q \notin\{0,1\}\end{cases}$

${ }^{q} D_{\beta}=\frac{{ }^{q} D_{\gamma}}{{ }^{q} D_{\alpha}}$.

For $q=0$ the generalized diversity ${ }^{0} D_{i}$ is simply the number of species present in particle $i$. To see that the generalized diversities are well-defined, we observe that ${ }^{q} H_{i}$ is maximized for $p_{i}^{a}=\frac{1}{A}$ (Theorem 1), so for $q>1$ we have
${ }^{q} H_{i} \leq \frac{1}{q-1}\left(1-A^{1-q}\right)<\frac{1}{q-1}$, which is within the domain of ${ }^{q} f$. For large $q$ the generalized diversity takes the limiting value of

$\lim _{q \rightarrow \infty}{ }^{q} D_{i}=\frac{1}{p_{i}^{\max }}$,

where $p_{i}^{\max }=\max _{a} p_{i}^{a}$ is the largest mass fraction of any species in particle $i$. This is the exponential of the minentropy ${ }^{\infty} H_{i}=-\ln \max _{a} p_{i}^{a}$ of particle $i$.

From the generalized diversities, we can now define the generalized mixing state index of order $q$ by

${ }^{q} \chi=\frac{{ }^{q} D_{\alpha}-1}{{ }^{q} D_{\gamma}-1}$.

The per-particle generalized diversity of order $q$ is illustrated in Fig. 10, and the population-level generalized diversities ${ }^{q} D_{\alpha}$ and ${ }^{q} D_{\gamma}$ behave similarly, with low-mass-fraction species ranging from equally important at $q=0$ to entirely irrelevant as $q \rightarrow \infty$.

The entropy and diversity measures defined in Sect. 2 are the $q=1$ case of the generalized entropy and diversity. An alternative derivation of the generalized diversity can be given using the Rényi entropy of order $q$ (Rényi, 1961, 1977), which is given by $\ln ^{q} D$. This latter definition was originally used by Hill (1973) to define the generalized diversities, for which reason these diversities are sometimes called Hill numbers in the ecology literature.

\section{Appendix B}

\section{Mathematical proofs}

In this section we give precise statements and proofs for the properties of the entropies, diversities, and mixing state index listed in Tables 3 and 5. While many of these facts are classical (MacKay, 2003; Tsallis, 2009), we restate them here in the aerosol particle setting for clarity, as well as adding results particular to aerosol particle populations and the mixing state index $\chi$. The provided proofs aim to capture the essential properties that lead to the results, rather than being exhaustive derivations. Although Tables 3 and 5 only summarize the properties for order parameter $q=1$, the results hold for all orders as indicated below, with $q=0$ typically having only sufficient conditions rather the necessary and sufficient conditions for positive orders.

The key observations that lead to the properties below are (1) the function ${ }^{q} H_{i}\left(p_{i}^{1}, \ldots, p_{i}^{A}\right)$ is concave (strictly concave for $q>0$ ); and (2) the map ${ }^{q} f$ is strictly increasing and convex on its domain (strictly convex for $q>0$ ). Both of these facts follow immediately from second-order derivative tests (Boyd and Vandenberghe, 2004, Sect. 3.1.4).

We use the notation $\mu_{i}=\left(\mu_{i}^{1}, \ldots, \mu_{i}^{A}\right)$ for the mass vector describing particle $i$, and we regard a particle population $\Pi$ 
as a multiset (Knuth, 1998, p. 473) of particle mass vectors. A multiset is, roughly speaking, a set where identical elements can appear multiple times, and for which the set difference operator $\backslash$ and union operator $\uplus$ have been appropriately extended.

Theorem 1. The diversities ${ }^{q} D_{i},{ }^{q} D_{\alpha}$, and ${ }^{q} D_{\gamma}$ all lie in the interval $[1, A]$ and ${ }^{q} D_{\alpha} \leq{ }^{q} D_{\gamma}$. Furthermore, for $q>0$, the extreme values satisfy: ${ }^{q} D_{i}=1$ if and only if particle $i$ is pure (consists of a single species); ${ }^{q} D_{i}=A$ if and only if particle $i$ contains all species in equal mass fractions, ${ }^{q} D_{\alpha}=$ 1 if and only if all particles are pure; ${ }^{q} D_{\gamma}=A$ if and only if all species are present with equal bulk mass fractions; and ${ }^{q} D_{\alpha}=D_{\gamma}$ if and only if all particles have identical species mass fractions.

Proof. Here we show the results for the entropies and this implies the corresponding results for the diversities because $q^{q} f$ is strictly increasing on its domain.

It follows immediately from the definition that ${ }^{q} H_{i} \geq 0$, and similarly for $H_{\alpha}$ and $H_{\gamma}$. The domain of allowable mass fractions $p_{i}^{a}$ is the probability simplex defined by $p_{i}^{a} \geq 0$ and $\sum_{a} p_{i}^{a}=1$, which has normal vector $(1,1, \ldots, 1)$. For $q>0$, ${ }^{q} H_{i}$ is a sum of identical functions of each component $p_{i}^{a}$ and so the gradient of ${ }^{q} H_{i}$ is in the direction of the normal vector if all $p_{i}^{a}$ are equal. The KKT conditions are thus satisfied for all mass fractions equal (Boyd and Vandenberghe, 2004, Sect. 5.5.3), and by strong convexity of ${ }^{q} H_{i}$ this is a unique maximum. Evaluating at $p_{i}^{A}=1 / A$ gives the maximum ${ }^{q} H_{i}=\ln A$. For $q=0$ the upper bound is immediate.

The condition for ${ }^{q} D_{\gamma}=A$ follows from the same argument as above applied to the bulk mass fractions $p^{a}$. The condition for ${ }^{q} D_{\alpha}=1$ is due to the fact that ${ }^{q} H_{\alpha}$ is the weighted arithmetic mean of the particle entropies with positive weights, so ${ }^{q} D_{\alpha}=1$ if and only if each ${ }^{q} H_{i}=0$.

The restriction ${ }^{q} H_{\alpha} \leq{ }^{q} H_{\gamma}$ is simply Jensen's inequality (Boyd and Vandenberghe, 2004, Sect. 3.1.8) for the concave entropy function. This can be seen by checking that $p^{a}=\sum_{i} p_{i} p_{i}^{a}$, and so the weights $p_{i}$ for combining ${ }^{q} H_{i}$ into ${ }^{q} H_{\alpha}$ are the same as for combining the per-particle mass fractions into the bulk mass fractions. For $q>0$, strict convexity of the entropy implies that Jensen's inequality is an equality if and only if the per-particle mass fractions are all identical.

Theorem 2. If population $\Pi^{1}$ evolves into population $\Pi^{2}$ by coagulation, then ${ }^{q} D_{\alpha}\left(\Pi^{2}\right) \geq{ }^{q} D_{\alpha}\left(\Pi^{1}\right),{ }^{q} D_{\gamma}\left(\Pi^{2}\right)=$ ${ }^{q} D_{\gamma}\left(\Pi^{1}\right),{ }^{q} D_{\beta}\left(\Pi^{2}\right) \leq{ }^{q} D_{\beta}\left(\Pi^{1}\right)$, and ${ }^{q} \chi\left(\Pi^{2}\right) \geq{ }^{q} \chi\left(\Pi^{1}\right)$. For $q>0$, equality in the preceding inequalities occurs if and only if all coagulating particles have identical mass fractions.

Proof. It is sufficient to consider a single coagulation event and then iterate the result, so without loss of generality we assume that $\Pi^{2}=\Pi^{1} \backslash\left\{\boldsymbol{\mu}_{i}, \boldsymbol{\mu}_{j}\right\} \uplus\left\{\boldsymbol{\mu}_{\mathrm{c}}\right\}$, where $\boldsymbol{\mu}_{c}=\boldsymbol{\mu}_{i}+\boldsymbol{\mu}_{j}$.

We observe that the total mass $\mu$ is preserved by coagulation and $p_{\mathrm{c}}=p_{i}+p_{j}$, where the mass fractions are com- puted with respect to the relevant population $\Pi^{1}$ or $\Pi^{2}$. Furthermore, $p_{\mathrm{c}} p_{\mathrm{c}}^{a}=p_{i} p_{i}^{a}+p_{j} p_{j}^{a}$ so concavity of the entropy gives $p_{\mathrm{c}}{ }^{q} H_{\mathrm{c}} \geq p_{i}{ }^{q} H_{i}+p_{j}{ }^{q} H_{j}$, with equality for $q>0$ if and only if $p_{i}^{a}=p_{j}^{a}$ by strict convexity. All other per-particle entropies in the populations are identical, so $p_{\mathrm{c}}=p_{i}+p_{j}$ implies ${ }^{q} H_{\alpha}\left(\Pi^{2}\right) \geq{ }^{q} H_{\alpha}\left(\Pi^{1}\right)$ with the same condition for equality.

Because the bulk mass fractions are unchanged by coagulation, ${ }^{q} H_{\gamma}\left(\Pi^{2}\right)={ }^{q} H_{\gamma}\left(\Pi^{1}\right)$ and the inequalities for ${ }^{q} H_{\beta}$ and $\chi$ follow immediately. The fact that $q_{f}$ is strictly increasing transfers all results to diversities.

Theorem 3. If populations $\Pi^{X}$ and $\Pi^{Y}$ are combined to give population $\Pi^{Z}=\Pi^{X} \uplus \Pi^{Y}$ then $\min \left({ }^{q} D_{\alpha}^{X},{ }^{q} D_{\alpha}^{Y}\right) \leq$ ${ }^{q} D_{\alpha}^{Z} \leq \max \left({ }^{q} D_{\alpha}^{X},{ }^{q} D_{\alpha}^{Y}\right), \quad \quad \min \left({ }^{q} D_{\beta}^{X},{ }^{q} D_{\beta}^{Y}\right) \leq{ }^{q} D_{\beta}^{Z}$, $\min \left({ }^{q} D_{\gamma}^{X},{ }^{q} D_{\gamma}^{Y}\right) \leq{ }^{q} D_{\gamma}^{Z}$, and ${ }^{q} \chi^{Z} \leq{ }^{q} \max \left(\chi^{X}, \chi^{Y}\right)$, where superscripts denote the population.

Proof. As ${ }^{q} f$ is strictly increasing it is sufficient to obtain bounds for entropies, which then imply bounds on the corresponding diversities.

Taking the total population mass fraction $\lambda=\mu^{Y} /\left(\mu^{X}+\right.$ $\left.\mu^{Y}\right) \in(0,1)$, then for particles $\mu_{x} \in \Pi^{X}$ and $\mu_{y} \in \Pi^{Y}$ the mass fractions in the combined population are $p_{x}^{Z}=(1-$ ג) $p_{x}^{X}$ and $p_{y}^{Z}=\lambda p_{y}^{Y}$. Thus ${ }^{q} H_{\alpha}^{Z}$ is the convex combination ${ }^{q} H_{\alpha}^{Z}=(1-\lambda)^{q} H_{\alpha}^{X}+\lambda^{q} H_{\alpha}^{Y}$ and so ${ }^{q} H_{\alpha}^{Z}$ lies strictly between ${ }^{q} H_{\alpha}^{X}$ and ${ }^{q} H_{\alpha}^{Y}$.

The bulk mass fractions satisfy $p^{Z a}=(1-\lambda) p^{X a}+\lambda p^{Y a}$ and so concavity of ${ }^{q} H_{\gamma}$ gives ${ }^{q} H_{\gamma}^{Z} \geq(1-\lambda)^{q} H_{\gamma}^{X}+\lambda^{q} H_{\gamma}^{Y} \geq$ $\min \left({ }^{q} H_{\gamma}^{X},{ }^{q} H_{\gamma}^{Y}\right)$.

To obtain the lower bound for ${ }^{q} H_{\beta}^{Z}={ }^{q} f^{-1}\left({ }^{q} D_{\beta}^{Z}\right)$, we observe that

${ }^{q} H_{\beta}=\frac{{ }^{q} H_{\gamma}-{ }^{q} H_{\alpha}}{1-(q-1)^{q} H_{\alpha}}$.

Using the expressions above for ${ }^{q} H_{\alpha}^{Z}$ and ${ }^{q} H_{\gamma}^{Z}$, this implies

$$
\begin{aligned}
{ }^{q} H_{\beta}^{Z} & \geq \frac{(1-\lambda)^{q} H_{\gamma}^{X}+\lambda{ }^{q} H_{\gamma}^{Y}-(1-\lambda)^{q} H_{\alpha}^{X}-\lambda{ }^{q} H_{\alpha}^{Y}}{(1-\lambda)+\lambda-(q-1)(1-\lambda)^{q} H_{\alpha}^{X}-(q-1) \lambda{ }^{q} H_{\alpha}^{Y}} \\
& =\frac{(1-\lambda)\left({ }^{q} H_{\gamma}^{X}-{ }^{q} H_{\alpha}^{X}\right)+\lambda\left({ }^{q} H_{\gamma}^{X}-{ }^{q} H_{\alpha}^{X}\right)}{(1-\lambda)\left(1-(q-1)^{q} H_{\alpha}^{X}\right)+\lambda\left(1-(q-1)^{q} H_{\alpha}^{Y}\right)} .
\end{aligned}
$$

Rearranging (B1) gives ${ }^{q} H_{\gamma}-{ }^{q} H_{\alpha}=\left(1-(q-1)^{q} H_{\alpha}\right)^{q} H_{\beta}$, so

$$
\begin{aligned}
{ }^{q} H_{\beta}^{Z} & \geq \frac{(1-\lambda)\left(1-(q-1)^{q} H_{\alpha}^{X}\right)^{q} H_{\beta}^{X}+\lambda\left(1-(q-1)^{q} H_{\alpha}^{Y}\right)^{q} H_{\beta}^{Y}}{(1-\lambda)\left(1-(q-1)^{q} H_{\alpha}^{X}\right)+\lambda\left(1-(q-1)^{q} H_{\alpha}^{Y}\right)} \\
& \geq \min \left({ }^{q} H_{\beta}^{X},{ }^{q} H_{\beta}^{Y}\right) .
\end{aligned}
$$


Finally, to obtain the upper bound for ${ }^{q} \chi^{Z}$ we again use the expressions for ${ }^{q} H_{\alpha}^{Z}$ and ${ }^{q} H_{\gamma}^{Z}$ to compute

$$
\begin{aligned}
{ }^{q} \chi^{Z} & =\frac{\exp \left({ }^{q} H_{\alpha}^{Z}\right)-1}{\exp \left({ }^{q} H_{\gamma}^{Z}\right)-1} \\
& \leq \frac{\exp \left({ }^{q} H_{\alpha}^{X}\right)^{(1-\lambda)} \exp \left({ }^{q} H_{\alpha}^{Y}\right)^{\lambda}-1}{\exp \left({ }^{q} H_{\gamma}^{X}\right)^{(1-\lambda)} \exp \left({ }^{q} H_{\gamma}^{Y}\right)^{\lambda}-1} .
\end{aligned}
$$

Recalling ${ }^{q} \chi \geq 0$, rearranging (B2) gives $\exp \left({ }^{q} H_{\alpha}\right)=(1-$ $\left.{ }^{q} \chi\right)+{ }^{q} \chi \exp \left({ }^{q} H_{\gamma}\right) \leq{ }^{q} \chi \exp \left({ }^{q} H_{\gamma}\right)$, so

$$
\begin{aligned}
{ }^{q} \chi^{Z} & \leq \frac{\left({ }^{q} \chi^{X} \exp \left({ }^{q} H_{\gamma}^{X}\right)\right)^{(1-\lambda)}\left({ }^{q} \chi^{Y} \exp \left({ }^{q} H_{\gamma}^{Y}\right)\right)^{\lambda}-1}{\exp \left({ }^{q} H_{\gamma}^{X}\right)(1-\lambda) \exp \left({ }^{q} H_{\gamma}^{Y}\right)^{\lambda}-1} \\
& \leq \max \left({ }^{q} \chi^{X},{ }^{q} \chi^{Y}\right),
\end{aligned}
$$

where we additionally used the bound ${ }^{q} \chi \leq 1$.

Acknowledgements. This research was supported in part by the US Department of Energy's Atmospheric System Research, an Office of Science, Office of Biological and Environmental Research program, under Grant No. DE-SC0003921 and in part by US EPA grant 835042. Its contents are solely the responsibility of the grantee and do not necessarily represent the official views of the US EPA. Further, US EPA does not endorse the purchase of any commercial products or services mentioned in the publication.

Edited by: M. Petters

\section{References}

Aczél, J. and Daróczy, Z.: On Measures of Information and their Characterizations, Academic Press, 1975.

Attaran, M. and Zwick, M.: An Information Theory Approach to Measuring Industrial Diversification, J. Econ. Stud., 16, 19-30, doi:10.1108/EUM0000000000124, 1989.

Bauer, S. E., Wright, D. L., Koch, D., Lewis, E. R., McGraw, R., Chang, L. S., Schwartz, S. E., and Ruedy, R.: MATRIX (Multiconfiguration Aerosol TRacker of mIXing state): An aerosol microphysical module for global atmospheric models, Atmos. Chem. Phys., 8, 6003-6035, doi:10.5194/acp-8-60032008, 2008.

Boyd, S. and Vandenberghe, L.: Convex Optimization, Cambridge University Press, 2004.

Chao, A. and Shen, T.-J.: Nonparametric estimation of Shannon's index of diversity when there are unseen species in sample, Acta Biotheor., 10, 429-443, doi:10.1023/A:1026096204727, 2003.

Chao, A., Jost, L., Chiang, S. C., Jiang, Y. H., and Chazdon, R. L.: A Two-Stage Probabilistic Approach to Multiple-Community Similarity Indices, Oikos, 64, 1178-1186, doi:10.1111/j.15410420.2008.01010.x, 2008.

Chao, A., Chiu, C. H., and Jost, L.: Phylogenetic diversity measures based on Hill numbers, Philos. T. Roy. Soc. B, 365, 3599-3609, doi:10.1098/rstb.2010.0272, 2010.

Ching, J., Riemer, N., and West, M.: Impacts of aerosol mixing state on aerosol activation and black carbon nucleation scavenging -
Insights from a particle-resolved model, J. Geophys. Res., 117, D23209, doi:10.1029/2012JD018269, 2012.

Chung, S. H. and Seinfeld, J. H.: Climate response of direct radiative forcing of anthropogenic black carbon, J. Geophys. Res., 111, D11102, doi:10.1029/2004JD005441, 2005.

Daróczy, Z.: Generalized information functions, Inform. Control, 16, 36-51, doi:10.1016/S0019-9958(70)80040-7, 1970.

De'ath, G.: The multinomial diversity model: linking Shannon diversity to multiple predictors, Ecology, 93, 2286-2296, doi:10.1890/11-2155.1, 2012.

DeVille, R. E. L., Riemer, N., and West, M.: Weighted Flow Algorithms (WFA) for stochastic particle coagulation, J. Comput Phys., 230, 8427-8451, doi:10.1016/j.jcp.2011.07.027, 2011.

Drucker, J.: Industrial Structure and the Sources of Agglomeration Economies: Evidence from Manufacturing Plant Production, Growth Change, 44, 54-91, doi:10.1111/grow.12002, 2013.

Falush, D., Stephens, M., and Pritchard, J. K.: Inference of population structure using multilocus genotype data: dominant markers and null alleles, Mol. Ecol. Notes, 7, 574-578, doi:10.1111/j.1471-8286.2007.01758.x, 2007.

Feoli, E.: Diversity patterns of vegetation systems from the perspective of similarity theory, Plant Biosyst., 146, 797-804, doi:10.1080/11263504.2012.740090, 2012.

Garrison, C. B. and Paulson, A. S.: An Entropy Measure of the Geographic Concentration of Economic Activity, Econ. Geogr., 49, 319-324, 1973.

Ghan, S. J. and Schwartz, S. E.: Aerosol properties and processes: a path from field and laboratory measurements to global climate models, B. Am. Meteorol. Soc., 1059-1083, doi:10.1175/BAMS-88-7-1059, 2007.

Good, I. J.: The population frequencies of species and the estimation of population parameters, Biometrika, 40, 237-264, doi:10.1093/biomet/40.3-4.237, 1953.

Goodman, D.: The Theory of Diversity-Stability Relationships in Ecology, Q. Rev. Biol., 50, 237-266, 1975.

Gorelick, R.: Commentary: Do we have a consistent terminology for species diversity? The fallacy of true diversity, Oecologia, 167, 885-888, doi:10.1007/s00442-011-2124-8, 2011.

Gotelli, N. J. and Chao, A.: Measuring and Estimating Species Richness, Species Diversity, and Biotic Similarity from Sampling Data, in: Encyclopedia of Biodiversity, 195-211, Elsevier, second edn., doi:10.1016/B978-0-12-384719-5.00424-X, 2013.

Hannah, L. and Kay, J.: Concentration in the Modern Industry: Theory, Measurement, and the U.K. Experience, MacMillan, London, 1977.

Harris, B.: The statistical estimation of entropy in the nonparametric case, Tech. Rep. 1605, Mathematics Research Center, University of Wisconsin-Madison, 1975.

Havrda, J. and Charvát, F.: Quantification method of classification processes. Concept of structural $a$-entropy, Kybernetika, 3, 3035, 1967.

Hill, M. O.: Diversity and Evenness: A Unifying Notation and Its Consequences, Ecology, 54, 427-432, 1973.

Hurlbert, S. H.: The Nonconcept of Species Diversity: A Critique and Alternative Parameters, Ecology, 52, 577-586, 1971.

Innan, H., Terauchi, R., Kahl, G., and Tajima, F.: A method for estimating nucleotide diversity from AFLP data, Genetics, 151, 1157, 1999. 
IPCC, 2007: Summary for Policymakers, in: Climate Change 2007: The Physical Science Basis. Contribution of Working Group I to the Fourth Assessment Report of the Intergovernmental Panel on Climate Change, edited by Solomon, S., Qin, D., Manning, M., Z. Chen, M. M., Averyt, K. B., Tignor, M., and Miller, H. L., Cambridge University Press, Cambridge, UK and New York, NY, USA, 2007.

Ives, A. R. and Carpenter, S. R.: Stability and Diversity of Ecosystems, Science, 317, 58-62, doi:10.1126/science.1133258, 2007.

Jacobson, M. Z.: Strong radiative heating due to the mixing state of black carbon in atmospheric aerosols, Nature, 409, 695-697, doi:10.1038/35055518, 2001.

Jacobson, M. Z.: Analysis of aerosol interactions with numerical techniques for solving coagulation, nucleation, condensation, dissolution, and reversible chemistry among multiple size distributions, J. Geophys. Res., 107, doi:10.1029/2001JD002044, AAC2-1-AAC2-23, 2002.

Jost, L.: Entropy and diversity, Oikos, 113, 363-375, doi:10.1111/j.2006.0030-1299.14714.x, 2006.

Jost, L., DeVries, P. J., Walla, T., Greeney, H., Chao, A., and Ricotta, C.: Partitioning diversity for conservation analyses, Divers. Distrib., 16, 65-76, doi:10.1111/j.1472-4642.2009.00626.x, 2010.

Jurasinski, G. and Koch, M.: Commentary: Do we have a consistent terminology for species diversity? We are on the way, Oecologia, 167, 893-902, doi:10.1007/s00442-011-2126-6, 2011.

Kaiser, J. C., Riemer, N., and Knopf, D. A.: Detailed heterogeneous oxidation of soot surfaces in a particle-resolved aerosol model, Atmos. Phys. Chem., 11, 4505-4520, 2011.

Knuth, D. E.: The Art of Computer Programming, vol. 2: Seminumerical Algorithms, Addison Wesley, 3rd edn., 1998.

Koch, D., Schulz, M., Kinne, S., McNaughton, C., Spackman, J. R., Balkanski, Y., Bauer, S., Berntsen, T., Bond, T. C., Boucher, O., Chin, M., Clarke, A., Luca, N. D., Dentener, F., Diehl, T., Dubovik, O., Easter, R., Fahey, D. W., Feichter, J., Fillmore, D., Freitag, S., Ghan, S., Ginoux, P., Gong, S., Horowitz, L., Iversen, T., Kirkevåg, A., Klimont, Z., Kondo, Y., Krol, M., Liu, X., Miller, R., Montanaro, V., Moteki, N., Myhre, G., Penner, J. E., Perlwitz, J., Pitari, G., Reddy, S., Sahu, L., Sakamoto, H., Schuster, G., Schwarz, J. P., Seland, Ø., Stier, P., Takegawa, N., Takemura, T., Textor, C., van Aardenne, J. A., and Zhao, Y.: Evaluation of black carbon estimations in global aerosol models, Atmos. Chem. Phys., 9, 9001-9026, doi:10.5194/acp-9-9001-2009, 2009.

Leinster, T. and Cobbold, C. A.: Measuring diversity: the importance of species similarity, Ecology, 93, 477-489, doi:10.1890/10-2402.1, 2012.

Liu, X., Easter, R. C., Ghan, S. J., Zaveri, R., Rasch, P., Shi, X., Lamarque, J.-F., Gettelman, A., Morrison, H., Vitt, F., Conley, A., Park, S., Neale, R., Hannay, C., Ekman, A. M. L., Hess, P., Mahowald, N., Collins, W., Iacono, M. J., Bretherton, C. S., Flanner, M. G., and Mitchell, D.: Toward a minimal representation of aerosols in climate models: description and evaluation in the Community Atmosphere Model CAM5., Geosci. Model Dev., 5, 709-739, doi:10.5194/gmd-5-709-2012, 2012.

MacArthur, R.: Fluctuations of Animal Populations and a Measure of Community Stability, Ecology, 36, 533-536, 1955.

MacKay, D. J. C.: Information theory, inference, and learning algorithms, Cambridge University Press, 2003.
Malizia, E. E. and Ke, S.: The influence of economic diversity on unemployment and stability, J. Regional Sci., 33, 221-235, doi:10.1111/j.1467-9787.1993.tb00222.x, 1993.

McCann, K. S.: The diversity-stability debate, Nature, 405, 228 233, doi:10.1038/35012234, 2000.

Moreno, C. E. and Rodríguez, P.: Commentary: Do we have a consistent terminology for species diversity? Back to basics and toward a unifying framework, Oecologia, 167, 889-892, doi:10.1007/s00442-011-2125-7, 2011.

Paninski, L.: Estimation of Entropy and Mutual Information, Neural Comput., 15, 1191-1253, doi:10.1162/089976603321780272, 2003.

Panzeri, S. and Treves, A.: Analytical estimates of limited sampling biases in different information measures, Comp. Neural Syst., 7, 87-107, doi:10.1088/0954-898X/7/1/006, 1996.

Patil, G. P. and Taillie, C.: An overview of diversity, in: Ecological Diversity in Theory and Practice, edited by: Grassle, J. F., Patil, G., Smith, W., and Taillie, C., 3-27, International Cooperative Publishing House, Maryland, USA, 1979.

Patil, G. P. and Taillie, C.: Diversity as a Concept and its Measurement, J. Am. Stat. Assoc., 77, 548-561, 1982.

Peet, R. K.: The Measurement of Species Diversity, Ann. Rev. Ecol. Syst., 5, 285-307, doi:10.1146/annurev.es.05.110174.001441, 1974.

Rényi, A.: On measures of entropy and information, in: 4th Berkeley symposium on mathematical statistics and probability, edited by: Neyman, J., 547-561, 1961.

Rényi, A.: Wahrscheinlichkeitsrechnung. Mit einem Anhang über Informationstheorie, vol. 54 of Hochschulbücher für Mathematik, VEB Deutscher Verlag der Wissenschaften, Berlin, 5th edn., 1977.

Riemer, N., Vogel, H., Vogel, B., and Fiedler, F.: Modeling aerosols on the mesoscale- $\gamma$ : Treatment of soot aerosol and its radiative effects, J. Geophys. Res., 108, 4601, doi:10.1029/2003JD003448, 2003.

Riemer, N., West, M., Zaveri, R. A., and Easter, R. C.: Simulating the evolution of soot mixing state with a particleresolved aerosol model, J. Geophys. Res., 114, D09202, doi:10.1029/2008JD011073, 2009.

Riemer, N., West, M., Zaveri, R. A., and Easter, R. C.: Estimating black carbon aging time-scales with a particleresolved aerosol model, J. Aerosol Sci., 41, 143-158, doi:10.1016/j.jaerosci.2009.08.009, 2010.

Rosenberg, N. A., Pritchard, J. K., Weber, J. L., Cann, H. M., Kidd, K. K., Zhivotovsky, L. A., and Feldman, M. W.: Genetic Structure of Human Populations, Science, 298, 2381-2385, doi:10.1126/science.1078311, 2002.

Scheiner, S. M.: A metric of biodiversity that integrates abundance, phylogeny, and function, Oikos, 121, 1191-1202, doi:10.1111/j.1600-0706.2012.20607.x, 2012.

Schmera, D. and Podani, J.: Components of beta diversity in hierarchical sampling designs: A new approach, J. Stat. Plan. Infer., 26, 126-136, doi:10.1016/j.ecolind.2012.10.029, 2013.

Simpson, E. H.: Measurement of Diversity, Nature, 163, 688-688, doi:10.1038/163688a0, 1949.

Stier, P., Feichter, J., Kinne, S., Kloster, S., Vignati, E., Wilson, J., Ganzeveld, L., Tegen, I., Werner, M., Balkanski, Y., Schulz, M., Boucher, O., Minikin, A., and Petzold, A.: The aerosol-climate 
model ECHAM5-HAM, Atmos. Chem. Phys., 5, 1125-1156, doi:10.5194/acp-5-1125-2005, 2005.

Stier, P., Seinfeld, J. H., Kinne, S., Feichter, J., and Boucher, O.: Impact of nonabsorbing anthropogenic aerosol on clearsky atmospheric absorption, J. Geophys. Res., 111, D18201, doi:10.1029/2006JD007147, 2006.

Strong, S., Koberle, R., de Ruyter van Steveninck, R., and Bialek, W.: Entropy and Information in Neural Spike Trains, Phys. Rev. Lett., 80, 197-200, doi:10.1103/PhysRevLett.80.197, 1998.

Tian, J., Riemer, N., Pfaffenberger, L., Schlager, H., and Petzold, A.: Modeling the evolution of aerosol particles in a ship plume using PartMC-MOSAIC, Atmos. Chem. Phys. Discuss., 13, 1673316774, doi:10.5194/acpd-13-16733-2013, 2013.

Toner, S. M., Sodeman, S. A., and Prather, K. A.: Single particle characterization of ultrafine and accumulation mode particles from heavy duty diesel vehicles using aerosol time-offlight mass spectrometry, Environ. Sci. Technol., 40, 3912-3921, doi:10.1021/es051455x, 2006.

Tsallis, C.: Possible generalization of Boltzmann-Gibbs statistics, J. of Stat. Phys., 52, 479-487, doi:10.1007/BF01016429, 1988.

Tsallis, C.: Introduction to nonextensive statistical mechanics, Springer, 2009.

Tsimring, L. S., Levine, H., and Kessler, D. A.: RNA virus evolution via a fitness-space model, Phys. Rev. Lett., 76, 4440-4443, doi:10.1103/PhysRevLett.76.4440, 1996.

Tuomisto, H.: A consistent terminology for quantifying species diversity? Yes, it does exist, Oecologia, 164, 853-860, doi:10.1007/s00442-010-1812-0, 2010.

Tuomisto, H.: Commentary: do we have a consistent terminology for species diversity? Yes, if we choose to use it, Oecologia, 167, 903-911, doi:10.1007/s00442-011-2128-4, 2011.
Tuomisto, H.: An updated consumer's guide to evenness and related indices, Oikos, 121, 1203-1218, doi:10.1111/j.16000706.2011.19897.x, 2012.

Tuomisto, H.: Defining, Measuring, and Partitioning Species Diversity, in: Encyclopedia of Biodiversity, 434-446, Elsevier, 2nd edn., doi:10.1016/B978-0-12-384719-5.00378-6, 2013.

Weingartner, E., Burtscher, H., and Baltensperger, H.: Hygroscopic properties of carbon and diesel soot particles, Atmos. Environ., 31, 2311-2327, doi:10.1016/S1352-2310(97)00023-X, 1997.

Whittaker, R. H.: Vegetation of the Siskiyou Mountains, Oregon and California, Ecol. Monogr., 30, 279-338, 1960.

Whittaker, R. H.: Dominance and Diversity in Land Plant Communities: Numerical relations of species express the importance of competition in community function and evolution, Science, 147, 250-260, doi:10.1126/science.147.3655.250, 1965.

Whittaker, R. H.: Evolution and Measurement of Species Diversity, Taxon, 21, 213-251, 1972.

Wilson, J., Cuvelier, C., and Raes, F.: A modeling study of global mixed aerosol fields, J. Geophys. Res., 106, 34081-34108, doi:10.1029/2000JD000198, 2001.

Zaveri, R. A., Easter, R. C., Fast, J. D., and Peters, L. K.: Model for simulating aerosol interactions and chemistry (MOSAIC), J. Geophys. Res., 113, D13204, doi:10.1029/2007JD008782, 2008.

Zaveri, R. A., Barnard, J. C., Easter, R. C., Riemer, N., and West, M.: Particle-resolved simulation of aerosol size, composition, mixing state, and the associated optical and cloud condensation nuclei activation properties in an evolving urban plume, J. Geophys. Res., 115, D17210, doi:10.1029/2009JD013616, 2010. 